\title{
Neurotrophins in lung health and disease
}

\author{
YS Prakash ${ }^{\dagger, 1,2}$, Michael A Thompson ${ }^{1}$, Lucas Meuchel $^{2}$, Christina M Pabelick ${ }^{1,2}$, Carlos B \\ Mantilla $^{1,2}$, Syed Zaidi ${ }^{3}$, and Richard J Martin ${ }^{3}$ \\ ${ }^{1}$ Department of Anesthesiology, Mayo Clinic College of Medicine, Rochester, MN 55905, USA \\ ${ }^{2}$ Department of Physiology and Biomedical Engineering, Mayo Clinic College of Medicine, \\ Rochester, MN 55905, USA \\ ${ }^{3}$ Department of Pediatrics, Rainbow Babies and Children's Hospital, Case Western Reserve \\ University, Cleveland, OH 44106, USA
}

\section{Abstract}

\begin{abstract}
Neurotrophins (NTs) are a family of growth factors that are well-known in the nervous system. There is increasing recognition that NTs (nerve growth factor, brain-derived neurotrophic factor and NT3) and their receptors (high-affinity TrkA, TrkB and TrkC, and low-affinity p75NTR) are expressed in lung components including the nasal and bronchial epithelium, smooth muscle, nerves and immune cells. NT signaling may be important in normal lung development, developmental lung disease, allergy and inflammation (e.g., rhinitis, asthma), lung fibrosis and even lung cancer. In this review, we describe the current status of our understanding of NT signaling in the lung, with hopes of using aspects of the NT signaling pathway in the diagnosis and therapy of lung diseases.
\end{abstract}

\section{Keywords}

asthma; bronchopulmonary dysplasia; development; fibrosis; inflammation; lung cancer; neurotrophic factor; rhinitis

\begin{abstract}
Normal lung development and continued lung health is key to prolong life expectancy. Lung diseases worldwide stem from a number of factors, such as developmental abnormalities, environmental exposures (e.g., tobacco smoke, chronic obstructive pulmonary disease, emphysema, cancers), industrial and workplace exposures (asbestosis, silicosis, lung fibrosis, cancers), allergies and inflammation (asthma, rhinitis, bronchitis, fibrosis) and genetic causes ( $\alpha-1$ antitrypsin deficiency, cancers). Given the wide range of lung diseases, the level of global healthcare and associated financial burden is simply massive. Accordingly, from both clinical and research perspectives, there is tremendous interest in understanding the mechanisms that contribute to normal lung development and lung health, and to the pathogenesis of different lung diseases. In this regard, based on the heterogeneity of lung components (airways, vasculature, interstitium, alveoli) and cell types, it is very likely that a number of complex and interactive mechanisms are involved. Nonetheless, certain mechanisms involved in regulating
\end{abstract}

\footnotetext{
(C) 2010 Expert Reviews Ltd

†Author for correspondence: Tel.: +1 507255 7481, Fax: +1 507255 7300, prakash.ys@mayo.edu.

Financial \& competing interests disclosure

YS Prakash is supported by NIH grants HL088029 and HL056470, and the Flight Attendants Medical Research Institute. Richard J Martin is supported by NIH grant HL056470 and Christina M Pabelick is supported by NIH grant HL090595. The authors have no other relevant affiliations or financial involvement with any organization or entity with a financial interest in or financial conflict with the subject matter or materials discussed in the manuscript apart from those disclosed.

No writing assistance was utilized in the production of this manuscript.
} 
lung structure and function may be common to different lung diseases. Recent and ongoing studies indicate that neurotrophic growth factors (neurotrophins [NTs]) may play such a role. In this article, we review the current understanding of NT physiology and its contribution to the structure and function of both the normal lung and a variety of lung diseases. The purpose of this review is to emphasize to the reader the potential of NTs in improving our understanding of the pathophysiology of lung health and disease, and their use as diagnostic markers and, perhaps, therapeutic targets.

\section{What are neurotrophins?}

The preponderance of scientific knowledge about NTs is based on studies in the nervous system, owing to their initial recognition in nerve outgrowth over 50 years ago $[1,2-6]$. Originating from the Greek (trophe) meaning nourishment, neurotrophism in the context of the nervous system refers to a nutritive, target-derived factor that promotes growth and survival of neurons. Indeed, since their initial description, NTs have been found to regulate neurogenesis, neuronal differentiation/survival, neuronal plasticity and neuronal conduction [6-9]. NTs are now thought to be involved in neurodegenerative disorders (e.g., Alzheimer's disease) [10,11], brain tumors [12], spinal cord injury repair [13] and other important clinical conditions [14].

While a number of pleotropic signaling molecules can regulate neuronal structure and function (and could thus be considered neurotrophic factors), classically, the NT family consists of just four polypeptides of similar structure and function: nerve growth factor (NGF), the first and best characterized NT, brain-derived neurotrophic factor (BDNF), NT3 and NT4 [3,7,15].

Neurotrophins are synthesized as prepro-protein precursors $(\sim 27 \mathrm{kDa})$ and are intracellularly cleaved into pro-NTs that are further processed to generate mature NTs of approximately 13 $\mathrm{kDa}[16,17]$. This final cleavage can occur intracellularly, or alternatively, NTs may be secreted in the pro-form and undergo extracellular cleavage into the smaller active peptides (mediated by factors such as plasmin and matrix metalloproteinases [MMPs]). The mature forms of the four mammalian NTs are 13-15 kDa polypeptides, all with extensive homology and structural similarities [18-20]. The mature forms of BDNF, NT4 and NT3 have approximately 50\% amino acid identity to NGF. Mature forms of all NTs are highly homologous (90-100\%) across species, which has greatly facilitated the use of animal models with exogenous administration of NTs and/or the use of transgenic animals lacking specific aspects of NT signaling pathways.

\section{Basics of neurotrophin signaling}

Neurotrophins exert their effects by binding to cell surface receptors (FIGURE 1). Two different receptors are involved. All NTs bind a low-affinity, $75 \mathrm{kDa}$ 'pan-NT' receptor p75NTR (dissociation constant $\left[\mathrm{K}_{\mathrm{d}}\right] 10^{-9} \mathrm{M}$ for NGF) that belongs to the TNF receptor family [21-23]. The family of high-affinity tropomyosin-related kinase (Trk) receptors $(\sim 140 \mathrm{kDa})$ consists of TrkA (which preferentially binds to NGF; $\mathrm{K}_{\mathrm{d}} 10^{-11} \mathrm{M}$ ), TrkB (which preferentially binds to BDNF and NT4), and TrkC (which preferentially binds to NT3) [3,4,6]. Additionally, pro-NTs can also bind to p75NTR; however, their signaling mechanisms are still under investigation. Nonetheless, the extracellular environment where NT cleavage occurs may determine whether it is the pro or the mature form that has biological activity on a cell.

All three Trk receptors are expressed in both full-length and truncated isoforms [3]. Biological activity requires the full-length receptor; however, the role of truncated isoforms is unclear. In this article, we will focus on data relating to the full-length receptor. Knockout mice data on neuronal survival suggest that Trk receptors are key to the biological activity of NTs. Lack of NT signaling can prevent full development and maturation of neuronal pools [24], and for some NT receptors, can result in early mortality (e.g., transgenic animals lacking TrkB die at a very 
early embryonic age). p75NTR also appears to be involved in neuronal survival, with mice lacking p75NTR showing a less severe phenotype. However, the exact role of p75NTR in vivo remains a puzzle $[4,21-23,25,26]$.

Both Trk and p75NTR receptors activate multiple, distinct signaling pathways [3,15,22]. Trks are tyrosine kinase receptors that dimerize and are autophosphorylated on intracellular tyrosine residues following NT binding, resulting in rapid (seconds to minutes) activation of downstream signaling cascades, including extracellular-regulated kinase, phosphoinositide-3 kinase/Akt (protein kinase B), and phospholipase $\mathrm{C} \gamma$ pathways. These important cascades can then activate cell-specific transcription factors involved in differentiation and survival, apoptosis and growth: events that occur over hours to days. Similar to other members of the TNF receptor family, p75NTR contains a death domain that docks with intracellular adapter proteins (following NT binding to p75NTR), which initiates downstream signaling events, for example those involving $\mathrm{NF \kappa B}$, that can inhibit apoptosis and/or promote cell survival [4,

22]. Overall, NTs can alter the balance between cell survival/growth and cell death $[4,22,23$, 26]. It is beyond the scope of this article to explore the diverse intra-cellular signaling mechanisms by which NTs produce their effects, which depend on cell type and environmental context. The reader is referred to excellent reviews on NT signaling included in the bibliography.

In addition to the now well-known 'genomic' effects of NTs (i.e., events occurring over hours to days and involving altered gene and protein expression triggered by NT stimulation), there is increasing recognition that NTs have relatively rapid, and probably 'non-genomic' effects that occur within seconds to minutes, and probably involve the high-affinity Trk receptors [5,27-29]. In this regard, the term 'non-genomic' refers to effects noted within these short time frames, and necessarily excludes subsequent genomic effects that may occur in response even to a brief stimulation with NTs. For example, at neuronal synapses, NTs are released in a $\mathrm{Ca}^{2+}$-dependent fashion akin to neurotransmitters (such as acetylcholine [ACh] and norepinephrine) and neuromodulators (such as serotonin, vasoactive intestinal peptide and substance P [SP]). NTs (especially BDNF) can modulate the efficacy of synaptic transmission by enhancing presynaptic neurotransmitter release [5]. Furthermore, NTs can directly modulate plasma membrane receptors (e.g., $N$-methyl-D-aspartate receptors), cationic channels (e.g., $\mathrm{Ca}^{2+}$ influx and voltage-gated $\mathrm{Na}^{+}$channels) and other mechanisms key to neuronal function [5,27-29].

These data demonstrate that NTs act on a diverse set of mechanisms and pathways that are not only important in the nervous system, but are common to almost all cell types in non-neuronal systems. By acting in a genomic (slow) versus non-genomic (rapid) fashion, NTs can regulate cell growth and survival, as well as more rapid signaling events such as ionic fluxes.

\section{Neurotrophins in non-neuronal tissues}

A diverse, heterogeneous distribution of Trk and p75NTR receptors along with NT production by different cell types of the CNS has been recognized. Since NTs are classically thought to arise from the targets of the nervous system (subserving a nutritive role for neurons), it is not surprising that organs such as skin, skeletal muscle, smooth muscle and other structural cells also secrete different NTs [30,31], with the assumption being that targets release such factors to regulate their own innervation in a positive or negative fashion. In support of this, Trk receptors have been found in the peripheral nervous system [32,33], where they may modulate synaptic transmission or induce long-term synaptic plasticity. For example, sensory neurons express TrkA (especially sympathetic and nociceptive neurons), TrkB and TrkC (other neurons), while p75NTR expression is more ubiquitous in sensory neurons. In addition to modulating neuronal survival, NTs may also regulate neuropeptides such as SP in nociceptive 
neurons. Recent studies show that presynaptic Trk receptors are expressed at the neuromuscular junctions of skeletal muscle such as the diaphragm, and NTs can acutely modulate neuromuscular transmission [34]. NTs can thus play a role in modulating nerve-target interactions outside the CNS. The overall effect of such interactions would be to structurally and functionally match the size and neuronal demand of target tissues with the extent or supply of innervation. Disruptions in nerve supply (e.g., denervation or nerve injury) would then trigger target-derived NTs to stimulate regeneration or plasticity of the remaining innervation.

There is increasing evidence that both low- and high-affinity NT receptors are widely distributed in non-neuronal tissues that are not necessarily associated with innervation, thus raising the issue of whether NTs released by peripheral tissues can have autocrine or paracrine effects on nearby structures other than nerves. In this regard, there appears to be tremendous heterogeneity in NT receptor expression by specific tissues, which is altered by age, disease and a number of conditions that cannot be adequately reviewed here. Most importantly, NTs and their receptors are widely expressed in the lung, and are consequently the focus of this article (see individual sections later). Apart from the lung, NTs and their receptors are also expressed in the nasal mucosa, skin, gastrointestinal and genitourinary systems, cardiac muscle, skeletal muscle and a variety of smooth muscles. Several clinically relevant conditions such as allergic skin disease [35], chronic constipation [36], coronary artery disease [37] and a number of cancers [12] are thought to involve dysregulation in NT signaling either through Trk receptors or through p75NTR.

\section{Neurotrophins in the lung}

A key issue in understanding the functions of NTs in the lung is the expression of the ligand protein versus cognate receptors in different cell types. Immunocytochemistry and other evidence suggests that both NTs and their receptors are expressed by a wide variety of component lung cells including nerves, immune cells, epithelium, smooth muscle, fibroblasts and vascular endothelium (see TABLE 1 and FIGURE 2) [38,39]. Accordingly, NTs have the potential to affect all aspects of lung structure and function. However, given the relatively recent (but increasing) recognition of NT signaling in the lung, information is limited to certain lung components and disease states. In the following sections, NT expression and signaling in various lung components is reviewed in the context of the clinically important diseases that they are involved in.

\section{Neurotrophins in immune cells}

A major stimulus for exploring NT signaling in the lung came from initial findings of enhanced serum NGF and BDNF levels in patients with allergic diseases, with very high levels in asthmatics [40] (recently reviewed in [41]). More recent studies have found elevated levels of NGF and BDNF in the peripheral blood of patients with allergic rhinitis [42]. Bronchoalveolar lavage with elevated levels of NGF and BDNF was reported in asthmatic patients as well as in mouse models of allergen challenge [41]. Nasal lavage of patients with allergic rhinitis shows elevated NGF levels (both at baseline and following allergic stimulation) compared with nonatopic controls [42]. While these data clearly show an association between NTs and allergic airway diseases, a topic of ongoing research is the source versus target of NTs. In this regard, there has been considerable work carried out on the expression of NTs and their receptors in immune cells. Within the lung, several types of immune cells can produce different NTs at baseline, or with stimulation (TABLE 1) $[41,43,44]$. Furthermore, some cell types also express NT receptors, either under normal conditions or with stimulation. Accordingly, NT signaling may be important in modulating and mediating allergic diseases.

Mast cells can produce NGF, BDNF and NT3, with triggered release of NGF upon IgE crosslinking, suggesting that allergens induce NT release in diseases such as asthma or rhinitis. 
Whether such triggered release occurs in the early-phase response (involving mast-cell degranulation) and, more importantly, modulates this response, is not clear. Nonetheless, the fact that NT levels remain sufficiently elevated to appear in lavages suggests that they may additionally influence the late-phase response (involving migration and infiltration by other immune cells, and increased airway reactivity).

Eosinophils have been shown to produce NTs both at baseline (NGF, BDNF, NT3) and following stimulation with NGF $[45,46]$. In patients with atopic dermatitis and allergic asthma, NT levels in blood eosinophils are elevated (e.g., NGF levels correlate with major basic protein levels) [47]. In vitro, stimulation of eosinophils with factors such as GM-CSF increases NGF and BDNF levels [46,48]. Conversely, NGF enhances IL-4 release from eosinophils [48], while NGF, NT3 and NT4 all promote eosinophil survival, especially in patients with allergic rhinitis [49]. NT receptors including p75NTR, TrkA, TrkB and TrkC have now been shown to be expressed on eosinophils [50]. TrkA receptor expression is increased in pediatric patients with allergic asthma or rhinitis [51].

Neurotrophin signaling also appear to be relevant to lung monocytes and macrophages, although this aspect is probably complex and is not completely understood (reviewed in [41]). Human monocyte-derived dendritic cells express both mRNA and protein for NGF and BDNF, and demonstrate increased BDNF generation and secretion (but not NGF) in response to lipopolysaccharide stimulation [52,53]. Alveolar macrophages constitutively express NT3, but produce NGF and BDNF in response to allergen challenge, while interstitial macrophages constitutively express BDNF [54]. One study reported NGF production by both $\mathrm{CD}^{+}$and $\mathrm{CD} 8^{+} \mathrm{T}$ lymphocytes [55], while another study showed NGF production by only $\mathrm{CD} 4^{+}$cells [56]. Increased NGF secretion by Th2 cells has been observed, which may be relevant to allergic asthma [55]. Constitutive BDNF expression by T lymphocytes appears to be enhanced after antigen challenge [57]. B cells are also known to produce NTs (NGF, BDNF and NT3), especially following antigen stimulation.

While these data clearly identify immune cells as a major source of NTs during inflammation, the targets of such NTs are still under investigation. It is likely that certain NTs modulate the activity of specific immune cells, and such interactions may be further affected by the cellular milieu. Rapid, non-genomic NT signaling (which has not been examined in these cell types) may acutely enhance or inhibit secretion of pro- vs anti-inflammatory cytokines, promote cell migration and further modulate the immune response. On a slower (probably genomic) scale, NTs may modulate the expression of cytokines and receptors in immune cells, even shifting the pattern of inflammation. Evidence for such NT effects has indeed been reported. For example, eosinophils can release IL-4 following NGF stimulation [48]. Human dendritic cells (which express TrkA and TrkB), are activated by NGF and BDNF (albeit via different signaling mechanisms), resulting in increased IL-6 production in allergic patients but IL-10 production in healthy patients [53]. While such complex roles and time courses for NT signaling remain to be more clearly delineated, the diverse data so far identify NTs and their receptors in immune cells as central components of inflammation and immune modulation in the lung and, thus, important aspects for a range of respiratory and lung diseases including rhinitis, bronchitis, asthma, lung injury and even cancer.

\section{Neurotrophins in the airway epithelium}

Given that the airway epithelium subserves a number of functions including acting as a barrier to allergens and infectious agents, a promoter and modulator of airway inflammation, and a source for bronchoconstrictive and bronchodilatory molecules [58], establishment of NT signaling in these resident cells would highlight the role of these molecules in airway function. Although there are very few studies on NTs in the airway epithelium $[39,59,60]$, immunocytochemical studies now show that the epithelium constitutively expresses NGF, 
BDNF and NT3. In mouse models of asthma, increased levels of epithelial BDNF have been reported $[60,61]$. Inflammatory Th1 cytokines such as TNF- $\alpha$ and IL-1 $\beta$ enhance epithelial NT production, at least in vitro [62].

While the limited data available support epithelial production of NTs, whether NTs modulate epithelial structure and function is not clear. In situ hybridization of mouse lung epithelia as well as immunocytochemistry of surgical samples from human lungs show NT expression, but not their receptors, suggesting that the airway epithelia may produce NTs but may not be the target [39]. However, recent studies have found that TrkA is expressed by human bronchial epithelial cells [60], and that epithelial cell death due to infection by respiratory syncytial virus (RSV) is enhanced in the absence of NGF [59], suggesting that NGF is a crucial survival factor for airway epithelia. More importantly, this study suggests that epithelia are a target of NTs. In lung alveoli, following injury, NGF enhances Clara cell proliferation and helps with repair of the lung [63]. In human nasal mucosa (which constitutively express NT receptors), BDNF and NGF are upregulated (but p75NTR expression may be downregulated) by allergen challenge [42].

In addition to regulating epithelial cell proliferation or survival, NTs may also have rapid (i.e., non-genomic) effects on the epithelium. In recently completed studies using isolated human bronchial epithelial cells, our group has discovered that BDNF and NT3, acting via TrkB and TrkC, respectively, can rapidly (i.e., within minutes) induce nitric oxide (NO) production, thus facilitating bronchodilation [64]. Such NO production is dependent on NT-induced elevation of intracellular $\mathrm{Ca}^{2+}$ concentration $\left(\left[\mathrm{Ca}^{2+}\right]_{\mathrm{i}}\right.$ ) and increased endothelial NO synthase (eNOS) phosphorylation. Prolonged exposure to NTs increases eNOS expression, thus priming the airway epithelium for enhanced NO production. Overall, these limited data at least suggest that NTs produced by airway epithelia (or other proximate sources such as airway innervation or immune cells) may have effects on both epithelial structure and function. Future studies should address how NT signaling (or its disruption) contributes to altered epithelial structure and function, particularly as it relates to barrier function (important in infection and environmental exposures) and airway remodeling (important in asthma).

\section{Neurotrophins in airway smooth muscle}

In addition to sources such as airway innervation and epithelium, there is increasing evidence that airway smooth muscle is also a potential source of NTs. For example, immunocytochemical studies of lung sections from non-asthmatic humans found that bronchial smooth muscle constitutively expresses NGF, BDNF and NT3 [39]. While TrkB expression was detected by immunocytochemistry, p75NTR was not. However, in isolated human bronchial smooth muscle cells, we found evidence for BDNF, NT4 and NT3, as well as TrkB, TrkC [65] and, more recently, p75NTR [66]. These data raise the possibility that, akin to epithelium, airway smooth muscle not only produces NTs, but also responds to them. In this regard, two aspects would be of relevance to airway contractility: rapid (non-genomic) modulation of airway smooth muscle function, and genomic effects such as cellular growth and proliferation. Indeed, in recent studies, we found that BDNF and NT4 acutely (within 30 min) enhance (while NT3 blunts) $\left[\mathrm{Ca}^{2+}\right]_{\mathrm{i}}$ and force responses of human airway smooth muscle to agonists such as ACh [65]. These data indicate that NTs, regardless of their source, can directly alter the contractility of airway smooth muscle, again via nongenomic mechanisms. Whether NTs also modulate airway smooth muscle proliferation is not known (although ongoing studies by our group support such an effect, mediated through NFKB). However, in vascular smooth muscle, NGF induces migration (but not proliferation) [67], while p75NTR activation induces apoptosis [68].

Inflammatory cytokines generally upregulate NT expression in airway smooth muscle, although these effects appear to be dependent on the cytokine and the NT. For example, in 
human bronchial smooth muscle cells, IL-1 $\beta$ increases NGF and BDNF and TNF- $\alpha$ increases BDNF and NT3, while IFN- $\gamma$ decreases BDNF (but increases NGF) [69]. These cytokines (especially TNF- $\alpha$ ) are now recognized as key players in asthma pathogenesis [70,71]. Accordingly, the effects of these cytokines on airway smooth muscle may be partly mediated by NTs. Indeed, in a recent study using human bronchial smooth muscle, we reported that TNF$\alpha$ increases TrkB and p75NTR expression, and that TNF- $\alpha$-induced enhancement of $\left[\mathrm{Ca}^{2+}\right]_{\mathrm{i}}$ responses to agonist (contributory to airway hyperresponsiveness following inflammation) is blunted by siRNA suppression of TrkB expression (but not p75NTR) [66]. An interesting but unexplored area is the potential synergistic effect of growth factors such as NTs and proinflammatory cytokines on airway smooth muscle proliferation and survival, since both NTs and cytokines such as TNF- $\alpha$ share common signaling mechanisms such as MAP kinases and PI3/Akt.

\section{Neurotrophins in airway innervation}

Neural control of the airway involves three peripheral autonomic pathways: adrenergically mediated bronchodilation (adrenal medulla or sympathetic ganglia); cholinergically mediated bronchoconstriction (involving the vagus); and the non-adrenergic/non-cholinergic (NANC) pathway with both bronchodilatory and bronchoconstrictive components [72-74].

Bronchodilation by NANC involves parasympathetic efferent neurons, vasoactive intestinal peptide and NO, while bronchoconstriction via NANC is mediated via subepithelial C-fiber sensory afferents that release tachykinins (neurokinin A and B, and SP) [75]. SP can contribute to local inflammation, immunomodulation and edema, thus substantially enhancing airway reactivity and contributing to diseases such as asthma. By virtue of being growth factors for neurons, NTs could potentially affect several neural mechanisms relevant to airway control.

In the human lung, Ricci et al. initially reported an obvious immunoreactivity for NTs (especially NGF and BDNF) in neurons and to a lesser extent in satellite cells of parasympathetic ganglia [39]. Surprisingly, ganglionic neurons of the lung did not display immunoreactivity for Trk receptors: only for p75NTR. However, nerve fiber-like profiles in lung sections displayed moderate immunoreactivity for both receptor types, perhaps representing the sympathetic component of airway innervation. Although these data nicely demonstrated NT and receptor presence in lung innervation, their functional role has only more recently been examined (reviewed in [76,77]). In mouse airway epithelium, NGF overexpression substantially increases SP content of sensory nerves [77]. Inflammation induced by allergens or virus (RSV in particular) can induce de novo neuropeptide production in vagal afferents (important for cough and sensing intrapulmonary stretch): changes mimicked by exogenous NGF administration. Similarly, in mice overexpressing NGF in airway tissue, increased sensory innervation has been reported [78]. Furthermore, these neurons express both TrkA and p75NTR and can thus respond to NGF (regardless of its source). Overall, these data demonstrate an important role for NGF in neural control of the airway.

The relevance of enhanced airway innervation or neurogenic stimulation lies in the increased sensitivity of the airway to stimuli in diseases, such as asthma, or with environmental exposures (allergens, cold, cigarette smoke and pollutants). In mice, exogenous NGF treatment results in airway hyperresponsiveness even in the absence of an asthma phenotype (induced by allergen sensitization and challenge) [77]. Furthermore, sensory neurons of mice overexpressing NGF show enhanced responses to capsaicin and hyper-innervation of SP-containing nerves [78]. In mice lacking p75NTR that were sensitized by allergen, airway hyperresponsiveness induced by capsaicin was severely blunted. Thus, NGF may be important in neurogenic airway hyperreactivity. In addition to NGF, BDNF may also play a role, since mice treated with functional antibodies against BDNF demonstrate reduced airway responsiveness to capsaicin [79]. 
Overall, these diverse data, while exclusively in animals, underline a central role for tachykinins of sensory nerves in mediating NT-induced hyperreactivity. What has been examined to a lesser extent is the mechanism by which NTs modulate the function of sensory neurons. One obvious mechanism is enhanced survival or expansion of receptive fields of sensory nerve endings, consistent with a growth factor effect of NTs. In addition to enhancing SP content in sensory neurons, NTs may upregulate neurokinin 1 receptor expression, as demonstrated by one study using NGF [51]. Airway inflammation in diseases such as asthma or bronchitis may lead to enhanced NT expression and release within the airway (from other cellular components), thus potentiating their effects on growth of airway nerves as well as signaling via neurokinin receptors for example. Such mechanisms have not yet been explored. Furthermore, the genomic effects of NTs on neuronal remodeling (e.g., expansion of receptive fields and receptor expression) versus rapid (non-genomic) effects (e.g., neuronal activity and synaptic transmission) have not been systematically examined.

\section{Neurotrophins in the pulmonary vasculature}

There is now some evidence that NT signaling may be important in the control of vascular structure and function [37,80-84]. In extrapulmonary branches of the human pulmonary artery, immunocytochemical studies show that NGF, BDNF and NT3 are present at comparable levels, particularly in the intima as well as the adventitia (with some reactivity in the inner layer of the smooth muscle media) [84]. Receptors for these NTs appear to be located in both the adventitial and intimal layers. These initial findings are strongly suggestive of a role for NTs in control of vascular responses via local autocrine or paracrine effects. The expression of both ligands and receptors in the intima raises the exciting possibility that NTs produced within the vascular wall can specifically influence the endothelium. This would be particularly important for the normal control of pulmonary vascular tone, as well as diseases such as pulmonary hypertension. While there is currently limited information on this subject, in recently completed studies using human pulmonary endothelial cells [85], we have found that even picomolar concentrations of BDNF as well as NT3 can induce NO production within 5 min, effects that are blunted by inhibition of eNOS, Trk or p75NTR receptors. Furthermore, in human pulmonary artery rings, these NTs induce acute vasodilation that is blunted by removal of the endothelium. In mouse pulmonary arteries, the low-affinity p75NTR receptor is expressed in both the endothelium and smooth muscle [80]. Furthermore, pulmonary artery rings from p75NTR knockout mice show significantly elevated contractions in response to endothelin-1 (but not other constrictors, suggesting the involvement of specific $\mathrm{Ca}^{2+}$ regulatory mechanisms). In addition to such acute, non-genomic effects, NGF and BDNF (via TrkA and TrkB, respectively) can also upregulate eNOS expression, and promote endothelial cell proliferation and survival [37]. Overall, NT signaling appears to be important in endothelial cell structure and function. Conversely, alteration in NT signaling may contribute to endothelial cell dysfunction. The importance of such effects in the pulmonary circulation has not been examined.

There are currently few data on the effect of NTs on pulmonary artery smooth muscle cells. In ongoing studies using human pulmonary-artery smooth-muscle cells [MEUCHEL L, THOMPSON MA, PABELICK CM, PRAKASH YS, UNPUBLISHED DATA], we have found that BDNF (to a greater extent that NT3) can increase $\left[\mathrm{Ca}^{2+}\right]_{\mathrm{i}}$ and potentiate vasoconstrictor-induced $\left[\mathrm{Ca}^{2+}\right]_{\mathrm{i}}$ responses. Furthermore, in endothelium-denuded pulmonary artery rings, BDNF potentiates endothelin-1 induced contractions. These limited data suggest that NTs (potentially derived from vascular innervation as well as other sources in the vascular wall) may acutely modulate pulmonary arterial tone. Given the proliferative/apoptotic effects of NTs in other cell systems, there is also the possibility that NTs may regulate the structure of the vascular wall. For example, in spontaneously hypertensive rats, expression of NGF, BDNF and their receptors is increased in the pulmonary vasculature, which displays substantial 
medial thickening [86]. In vascular smooth muscle cells derived from the systemic circulation, NTs are secreted in a regulated fashion and these cells respond to NTs by increasing proliferation. Indeed, NGF is now known to induce and enhance angiogenesis, especially during development [37]. These emerging data highlight a novel regulatory mechanism for control of vascular tone in the lung. The contrasting effects of NTs on NO production (vasodilation) versus contraction and proliferation of smooth muscle raises the possibility that in diseases such as pulmonary hypertension, NTs may be used to reverse the imbalance of impaired vasodilation versus excessive vasoconstriction.

\section{Neurotrophins in lung development}

While NT signaling is now known to be important for embryonic development of both the central and peripheral nervous systems [3], there are considerably less data on their role in the development of non-neuronal structures. Mouse studies on developmental changes in NT expression have found a dynamic pattern of increasing versus decreasing levels of NGF versus BDNF in whole-lung lysates [87]. However, given the differential expression of NTs and their receptors in different lung components, it is difficult to determine the functional relevance of such findings. Unfortunately, more detailed studies on NTs in lung development are severely limited by the early mortality of transgenic animals lacking NT receptors, especially highaffinity receptors. However, a single study has examined TrkB during lung development in the mouse, comparing wild-type animals with those carrying a $\operatorname{trk} B$ gene mutation that produces a nonfunctional protein (resulting in a lifespan of only a few weeks) [88]. In the lungs of wildtype animals, mRNA for TrkB was higher at 15 days postnatal, and decreased progressively and substantially with age in all components. Neuroepithelial bodies as well as innervation of the airway and vasculature were found to have high TrkB expression. TrkB was also found in bronchial epithelial cells, with variable expression elsewhere. Transgenic animals with nonfunctional TrkB displayed thinner bronchial epithelium, larger luminar airway diameter, and larger air spaces, but thickened vascular walls compared with wild-type animals. Interestingly, another study found that the absence of BDNF does not appear to significantly affect lung development [89]. However, given the potential redundancy between BDNF and NT4, this does not necessarily rule out a role for NTs in lung development. Overall, these limited data suggest that NTs are somehow involved in lung development, potentially by affecting neuronal regulation of growth and proliferation of different lung elements. However, the presence of NT receptors in other lung components suggests a more complex physiology that remains unexplored. In this regard, a potentially elegant technique to examine the role of NT signaling in lung development is the use of a 'knock-in' mouse model [90]. Here, small molecule inhibitors of mutated Trk receptor tyrosine kinase domains allow for normal receptor function until the kinase activity is transiently and reversibly inhibited by administration of the inhibitor (e.g., via the animals' water supply) [90]. Such models have been used to examine NT signaling in other tissues, and studies in the lung are awaited.

\section{Neurotrophins in neonatal lung disease}

Preterm birth and neonatal lung injury, characterized by bronchopulmonary dysplasia, are associated with a high incidence of childhood asthma [91]. A well-characterized model for broncho-pulmonary dysplasia (BPD) is neonatal hyperoxic exposure in rat pups, which is associated with increased cholinergically mediated airway and lung parenchymal contractile responses in vitro and in vivo (reviewed in [92]). However, there is no widespread consensus as to by what mechanisms cholinergic effects are up regulated under these conditions. With this background, Martin and colleagues have evaluated the effects of hyperoxia on lung expression of BDNF, NGF and Trk receptors [92,93]. In 5-day old rat pups, 7 days of continuous hyperoxia (95\% oxygen) exposure increases BDNF levels (mRNA and protein) compared with normoxic, age-matched controls. Distribution of BDNF mRNA by in situ 
hybridization indicated that peribronchial smooth muscle was the major source of increased BDNF production in response to hyperoxic exposure. Interestingly, hyperoxia-induced elevation of BDNF was not accompanied by any changes of NGF levels in the lung (in contrast to findings with RSV infection in neonates [94]). Furthermore, hyperoxic exposure increased peribronchial smooth muscle TrkB expression (but not TrkA). These findings indicate that hyperoxic stress not only up regulates BDNF but also enhances TrkB, raising the possibility that upregulation of NTs may contribute to airway reactivity under certain pathophysiological states associated with neonatal lung injury, asthma and other inflammatory airway diseases in children [92]. This hypothesis is also consistent with the prior observation that BDNF is expressed in airway preganglionic neurons in the brainstem [95], and confirms a role for NTs in neural control of the airways. Here, hyperoxic exposure of 5-day-old rat pups for 7 days substantially increases ACh content in the lung (compared with normoxic controls), an effect inhibited by the tyrosine kinase inhibitor K-252a. These findings suggest that BDNF and TrkB signaling may participate in a centrally or peripherally induced increase in ACh production and resultant cholinergic outflow to the airways under conditions of hyperoxic stress [96]. In a physiologic correlate to these findings and as expected, hyperoxia increased contraction (and impaired relaxation) of lung strips in vitro; effects blunted by K-252a (with no apparent changes induced by K-252a in normoxic controls) [96]. In support of this, exogenous BDNF enhances contractions in lung strips (again blunted by the tyrosine kinase inhibitor or the BDNF chelating TrkB-Fc chimeric protein). Overall, these data show that hyperoxic exposure in neonatal rats increases BDNF-TrkB signaling in the lung, and modulates the contractile function of peripheral airways exposed to hyperoxia in early life. Further studies are needed to characterize the basic cellular and molecular mechanisms whereby BDNF modulates these responses.

Furthermore, pharmacological modulation of BDNF-TrkB receptor signaling may serve as a potentially useful line of investigation in the treatment of airway hyperreactivity elicited by pathophysiological states such as neonatal hyperoxic exposure (i.e., BPD).

\section{Neurotrophins in rhinitis}

Although there is currently limited knowledge regarding NTs in nasal mucosal immunity and function, the data appear to point to these factors being important in the pathophysiology of rhinitis $[42,45,50,97,98]$. There were initial reports of increased serum NGF levels in patients with allergic rhinitis, followed by reports of increased BDNF levels. At a local level, nasal lavage fluids of patients with rhinitis display higher NGF levels compared with nonatopic controls. Importantly, allergen challenge of the nasal passageway enhances lavage NGF levels, especially in patients with rhinitis. More recent data show that NGF is expressed within glands of the nasal epithelium, innervation of the nasal mucosa and in eosinophils of patients with allergic rhinitis. Nasal BDNF expression also appears to be increased following allergen challenge in patients with rhinitis.

As with other conditions, these data raise the question of NT targets in the nasal passageway. On the other hand, p75NTR is expressed by nasal epithelium, innervation and mucosa in allergic rhinitis. However, p75NTR expression in the mucosal innervation is actually decreased in rhinitis, making the role of NT signaling via this mechanism unclear. On the other hand, TrkA has been localized to the nasal epithelium, innervation and submucosa, suggesting that NGF at least may act on all these structures. However, the effects NGF has on the cells of these structures remains unknown. Regardless, one likely target of NGF (and even BDNF) is eosinophils, which express and respond to these NTs, displaying enhanced degranulation (e.g., of eosinophil protein X) and production of inflammatory molecules (e.g., IL-4) [48]. 


\section{Neurotrophins in asthma}

Diseases such as asthma involve inflammation, airway obstruction and airway hyperresponsiveness. In this regard, structural elements of the airway not only respond to inflammation, but may themselves produce a number of pro- and anti-inflammatory mediators. Inflammation leads to increased contractility (and impaired relaxation) as well as structural remodeling of the airway, the latter being characterized by thickening of the basement membrane, goblet cell hyperplasia, hypertrophy and proliferation of airway smooth muscle and enhanced innervation.

With evidence for NT signaling in airway innervation, epithelium and smooth muscle, and in immune cells, there is currently significant interest in the potential role of NTs in asthma $[41,43,66,76,77,99-103]$. Allergen challenge has been found to increase NGF, BDNF and NT3 levels in bronchoalveolar lavage fluid in humans [40] and in mouse models of allergic asthma [104]. Based on the earlier discussion of NT and receptor expression across different lung components, NTs may work via several mechanisms in contributing to asthma. Several types of immune cells (including dendritic cells, mast cells, macrophages and lymphocytes) express NTs as well as their receptors (TABLE 1). Accordingly, NTs may modulate the sensitization to allergen challenge and the inflammatory response pattern. NTs may additionally affect neural control of the airway, modulating bronchonconstrictor release and airway hyperreactivity. Based on data showing NO release [64], NTs may modulate epitheliumderived bronchodilator responses (and perhaps epithelial regulation of inflammation). Airway smooth muscle contractility may be enhanced, particularly in the presence of inflammatory cytokines [66]. Finally, NTs may modulate airway remodeling. Here, NGF has been shown to increases fibroblast migration and myofibroblast differentiation [105,106]. Bronchial smooth muscle is key to the remodeling process (via proliferation, migration and secretion of inflammatory mediators and modulators, such as MMPs which cleave pro-NTs) [107-109]. A single study has found that BDNF, NT3 and NGF all increase MMP9 (but not MMP2), while BDNF and NT3 enhance smooth muscle migration [101]. Based on these diverse data, it is very likely that NTs play a key role in asthma.

\section{Neurotrophins \& environmental exposures}

Both outdoor and indoor air pollutants are risk factors in the development of allergic diseases such as asthma and rhinitis and for respiratory infections. Factors such as active smoking as well as second-hand smoke exposure can potentiate the effects of other allergens. Considering the increasing evidence for NTs as mediators or modulators of allergic disease, subsequent studies have examined the effect of environmental exposures on NT expression and signaling. For example, in mice, low levels of toluene exposure was found to enhance allergic lung inflammation [110-112]. Furthermore, the combination of toluene and allergen substantially increased plasma NGF levels. In patients with atopic keratoconjuctivitis (where NGF, BDNF and NT3 levels are all elevated in tears compared with healthy controls), passive smoking significantly elevates NT levels [113]. Expression of NGF as well as p75NTR receptors (but not Trk receptors) is increased in the lungs of rats exposed to nicotine [114]. RSV infection after chronic nicotine exposure produced an additive effect on NGF expression, with potentiation of neurogenic airway inflammation - effects reversed by a functional inhibitor of NGF. In ongoing studies using human bronchial epithelium as well as airway smooth muscle [SATHISH V, PABELICK CM, PRAKASH YS, UNPUBLISHED DATA], we have found that exposure to cigarette smoke substantially increases both TrkB and p75NTR expression by these airway components. Furthermore, in airway smooth muscle cells exposed to cigarette smoke, $\left[\mathrm{Ca}^{2+}\right]_{\mathrm{i}}$ responses to histamine are enhanced. Exogenous addition of BDNF substantially potentiates these effects, while inhibition of TrkB or p75NTR blunts cigarette smoke-induced enhancement of $\left[\mathrm{Ca}^{2+}\right]_{\mathrm{i}}$ responses. These limited data point to participation of 
NTs in enhanced airway inflammation and reactivity following environmental exposures. In response to such exposures (especially in the presence of allergens), NTs may enhance neuronal-immune interactions in the airway as well as airway remodeling, thus contributing to increased airway irritability and hyperresponsiveness.

\section{Neurotrophins in pulmonary fibrosis}

As with many other diseases, there is limited information on the role of NTs in pulmonary fibrosis $[38,115]$. Here, it is important to note that pulmonary fibrosis represents a wide range of etiologies and pathophysiologies, which makes placement of NTs into the signaling networks of fibrosis mechanisms somewhat difficult. One in vitro study found that human pulmonary fibroblasts constitutively secrete NGF [116], and that NGF secretion was enhanced by proinflammatory cytokines such as IL- $1 \beta$ and TNF- $\alpha$. NGF is known to promote mesenchymal cell proliferation, which should result in enhanced production of extracellular matrix components, thus contributing to fibrosis [106]. A single immunocytochemical study found increased NGF and TrkA expression in the lungs of patients with idiopathic pulmonary fibrosis/usual interstitial pneumonia [38]. Areas rich with fibroblasts also stained for BDNF and TrkB. Fibroblasts derived from such patients showed higher proliferative rates in response to BDNF as compared with controls. In culture, NGF induces p75NTR expression in human lung fibroblasts, and stimulates fibroblast migration and increased contraction of a collagen gel. However, another study has found that NGF does not promote survival of human lung fibroblasts in vitro, but does stimulate TrkA expression, without affecting cytokine signaling, thus indicating that NGF released by fibroblasts (e.g., during inflammation) is not associated with increased proinflammatory factors [117]. While these limited data suggest that NT expression is altered in lung fibrosis, there is currently no clear information on whether and how NTs are involved in actually mediating or modulating the pathophysiology of fibrosis.

\section{Neurotrophins in lung cancer}

Neurotrophins are known to be involved in the malignant transformation of several solid tumors and blood-borne cancers $[12,118]$. Tumors may both produce NTs as well as respond to these factors (potentially derived from proximate sources). Thus, there is significant interest in understanding the role of NTs in cancer. In this regard, NTs and their receptors are have been localized to lung cell lines and tumors [88,119-121]. For example, NGF has been found in bronchoalveolar and squamous cell carcinomas, and BDNF in small-cell lung cancers [119]. Typical carcinoids express NGF to a greater extent than atypical carcinoids (which express more BDNF) [120]. High levels of TrkA and TrkB (but not TrkC) have been found in human lung adenocarcinoma and squamous cell carcinomas [119], while TrkB has been found in small cell lung cancers and atypical carcinoids [120]. The expression of both ligand and receptor within the same type of lung cancer raises the possibility of autocrine/paracrine effects. In vitro, NGF inhibits the growth of tumor cells derived from small cell lung cancer, and decreases their tumorigenic potential in mice [122]. Conversely, lack of NGF signaling promotes tumor cell apoptosis. On the other hand, survival of the human lung adenocarcinoma cell line A549 is enhanced by NGF or BDNF, while inhibition of Trk signaling induces cell death [121]. Whether other NTs have similar anti-cancer effects is not known. In this regard, an interesting observation is that p75NTR does not appear to be expressed in lung cancers. Given the potential role of this receptor in mediating cellular death, its absence may contribute to cancer progression. Therefore, the relative expression of NTs, Trk and p75NTR expression within a tumor may be important in determining the net effect on tumor progression or growth.

Regardless of their effect on tumor cells per se, NTs may indirectly modulate tumor growth by virtue of their angiogenic properties [37,81]. It is tempting to speculate that highly vascularized tumors may express higher levels of NTs that not only promote growth/ 
proliferation of the cancer cells, but perpetuate this cycle by maintaining or enhancing tumor blood supply. Accordingly, interference with NT expression and/or signaling may help to reduce tumor burden. Unfortunately, there are no data on this theme in lung cancers.

\section{Heterogeneity of neurotrophin \& receptor expression in the lung}

From the data so far, there is clearly heterogeneity in NT expression and function within the lung, with NGF and increasingly BDNF appearing to be the key players. While NT3 may also be involved (especially in smooth muscle, where its role may be the opposite of other NTs), its role remains to be better defined. Within a cell type in the lung, the net effect of a single NT will depend on the relative expression of the different Trk receptors and p75NTR, along with any interactions between these receptors. The evidence to date indicates that the lung heterogeneously expresses both Trk and p75NTR receptors. However, the role of p75NTR remains a puzzle (and not just in the lung). In some cells, NT activation of p75NTR facilitates apoptosis, while in others the same NT-p7NTR combination facilitates cell growth and survival. An emerging picture regarding this apparent discrepancy is that p75NTR partners with other coreceptors within a cell to modulate cell- and context-specific responses by recruitment of intracellular binding proteins and the activation of different signaling pathways $[22,23,26]$. An obvious partner for p75NTR here would be the Trk receptors, although there is now evidence that p75NTR can partner with several other receptor classes to produce different effects [123]. Accordingly, relevant to lung structure and function, the relative expression (and functionality) of p75NTR versus different Trk receptor subtypes (along with other regulatory molecules) probably determines the net effect of NTs. This is exemplified by the fact that in some immune cells TrkA and p75NTR may be expressed, while in others TrkB may partner with p75NTR. Considering the fact that the Trk receptors themselves differ somewhat in the activation of specific intracellular cascades, this only raises the level of complexity (and diversity) of p75NTR effects. There are currently no data on these types of interactions within the lung.

Even for Trk signaling alone, the story is not straightforward. Most cells in the lung appear to express multiple Trk receptor subtypes. Although Trk receptors are preferentially activated by certain NTs (e.g., NGF for TrkA), there is some overlap. As mentioned earlier, Trk receptor subtypes may also differ in their activation of signaling cascades, which may be cell-specific and dependent on the relative expression of intracellular signaling cascades. Accordingly, for a particular cell type in the lung, even a single NT has the potential to activate different Trk receptors (along with p75NTR if it is expressed). These issues are further complicated by the effect of disease (especially involving inflammation) on the relative expression of Trk receptors, with probable changes in the intracellular cascade milieu. Another important aspect of Trk signaling that has not been well studied in the lung is that of full-length (Trk-FL) versus truncated Trk isoforms (Trk-T) 1 or Trk-T2. While NTs can specifically bind to either isoform, only the Trk-full length has the kinase and associated domains to activate subsequent intracellular cascades. The roles of Trk-T1 and Trk-T2 isoforms are still under investigation, but it is likely that by binding NTs, these truncated isoforms can inhibit NT effects on cells. Accordingly, the relative expression of full-length versus truncated isoforms is key to determining NT effects. There is some evidence that many lung cell types mostly express truncated isoforms and therefore under normal conditions the unwanted effects of NTs may be suppressed [54,124]. However, with disease, the ratio of full-length to truncated isoforms may increase, thus allowing NT effects. Here, depending on the Trk receptor subtype involved, there may be qualitative and quantitative differences. These issues have not been systematically examined. 


\section{Neurotrophins as diagnostic \& prognostic markers}

It is important to consider whether NTs can be used as diagnostic markers in assessing lung health or in classifying the identity and severity of diseases. Elevated NT levels in nasal and bronchoalveolar lavages in rhinitis and other allergic diseases along with a correlation between NT expression and disease severity, are now recognized. For example, higher levels of NTs in upper airways after nasal allergen provocation with correlated clinical symptoms may be important in understanding pathophysiological changes in mucosal immunity, inflammation and neuroimmune interactions. Production of NTs may be a biological response to maintain or restore homeostatic functions in nasal tissues. As we expand our understanding of how NTs work within each cell type of the lung, and are affected by disease, it is exciting to speculate that expression of specific NTs and/or receptors in particular lavage fluids, immune cells and epithelia derived from biopsies can be used for the diagnosis of disease type and severity, as well as to follow the outcome of therapy. Once we understand which signaling cascades are activated or inhibited by NTs under normal conditions versus during disease, the responses of sample/biopsy-derived cells in vitro may also be used for diagnostic purposes. In this regard, it will be important to first determine 'normal' levels of NTs in blood, nasal or bronchoalveolar lavage, and the extent of change in specific diseases.

\section{Neurotrophins as therapeutic targets}

Over the past 30 years, the role of NTs in the nervous system has became well established, and there is now tremendous interest in manipulating NT signaling as a therapeutic avenue for diseases such as Alzheimer's and depression. In this regard, it is impressive (and intriguing) that NTs appear to also be important in the lung, and not just for neural control of different components. From the perspective of understanding normal lung biology as well as of exploring mechanisms and therapeutic options for a wide range of lung diseases, NTs therefore represent an attractive area of research emphasis. Conversely, the summary of current knowledge as briefly outlined in our review suggests that the pleiotropic effects of NTs on different lung components, as well as differences in expression, function and signaling of different NTs within the various lung components, clearly make this a challenging area. While there has been substantial progress in our understanding of signaling by NTs in different cell systems, there are still a number of confounding issues (especially relating to cell-specific and NT-specific heterogeneities in expression and function). However, with ongoing advances in research techniques and a greater understanding of NT signaling in other tissues, there is much hope that NTs will continue to be a major research focus in lung biology and pathophysiology, and, in the near future, a therapeutic avenue in lung disease.

Since different lung components do not express (or respond to) the same NT (see TABLE 1 and earlier discussions), site-specific targeting of NTs for therapy in lung disease may be a challenge. Approaches such as nanoparticle technology and cell-specific markers to facilitate the preferential uptake of NTs by cells of interest (e.g., immune cells vs epithelium vs smooth muscle), viral vectors or cellular scaffolds may be required. Here, the airway epithelium and underlying innervation may be an attractive target since NT (or molecules activating or inhibiting specific NT receptors) may be administered via the airway to achieve high local levels, but low systemic levels. Simple NT nebulization or intratracheal administration has been performed in animal studies, although it is not clear that the extent of penetration of these molecules into the lung, local versus systemic levels, or degradation or elimination of NTs, has actually been determined.

Considering the extensive expression of NTs and/or their receptors at different levels in the lung, yet recognizing the complexities of their signaling, an obvious question is which diseases, mechanisms or specifc cell types should be targeted when planning a therapeutic future for 
NTs. Certainly, based on accessibility, as already mentioned, the nasal passages and airway epithelium are good choices. Assuming systemic administration of substances that activate or interfere with NT signaling becomes feasible, immune cells may be additional option.

However, these approaches may be more relevant to specific conditions. For example, in diseases such as rhinitis, asthma or other reactive airway diseases, targeting nasal mucosa, epithelium and/or innervation is attractive. Given the important role for inflammation in these diseases, both localized and systemic administration may be possible. Targeting cancers may also be possible, depending on the location and features of the tumor including type, vascularization and NT or receptor profile. However, it must also be noted that these diseases are multifactorial in origin, and differ in their immune and inflammation profiles, and in the way in which resident cells will be altered in their signaling profiles. Therefore, it may also be important to selectively target only certain cell types and not others.

In terms of therapeutic potential, NTs have already been considered for diseases of the nervous system such as Alzheimer's disease [11] and peripheral neuropathy [125], with some success in early trials (although this has not been replicated in larger trials). However, an important limitation in the nervous system is the inability of candidate molecules to cross the blood-brain barrier. This may be less of a problem in the lung; however, access to deeper structures in the lung may not be feasible with inhalational approaches and may require systemic administration resulting in higher NT levels. Alternatively, gene therapy or cell-based gene delivery may be possible, obviating changes in NT levels except by the cells targeted. Small molecule activators (or inhibitors) of Trks versus p75NTR (depending on the situation) are attractive options [12, $15,126,127]$. Alternatively, molecules that bind extracellular NTs and prevent their action could be used. While these options are being aggressively pursued in the laboratory, to date, NTs have not proven their therapeutic potential, perhaps mainly owing to their pharmacokinetic profiles. Further research in this area is anticipated.

Most of the work on NTs in the lung has focused on normal health and disease of the adult lung. However, as exemplified by our work and by a few others, there is clearly a role for NT signaling in lung development and airway diseases in children such as BPD and asthma. Considering the potential long-term benefit of treating these diseases, much more study is required to aid understanding of NT signaling in the developing lung.

\section{Expert commentary}

While signaling via NTs in different lung components has now been recognized, what is yet to be identified is a coherent physio logical model for NT function in the lung. A number of questions can be asked:

- Under normal conditions, where are NTs largely derived from and what are their primary targets? As outlined in this article, these issues are quite complex, since it appears that many lung components either express different NTs or respond to them, sometimes in different ways;

- If NTs are widely expressed, from an evolutionary standpoint, what is the intended function of NTs in the lung: is it to modulate neurogenic tone of airways and vasculature (as some neuro-modulators do), or to modulate immune function? Here the answer may be in the affirmative on both aspects. Furthermore, NTs can have both acute effects, such as NO production by epithelium and increased $\left[\mathrm{Ca}^{2+}\right]_{\mathrm{i}}$ in smooth muscle, as well as genomic effects following prolonged exposure. The relative importance of these effects depends on the source of NTs. On the one hand, if NTs are released by airway and vascular nerves akin to neurotransmitters (or even by immune cells in bursts), such events will be phasic and acute, and thus bronchial and vascular constriction versus dilation may be key. On the other hand, circulating NT 
levels as well as those released by airway epithelium or smooth muscle may result in prolonged receptor stimulation that may lead to a different signaling cascade. Here, the relative roles of high-affinity Trk receptors versus low-affinity p75NTR receptors may be important (but have not been well studied);

- Given the important role for NTs in neuronal development and aging, is there a similar role for NTs in lung development and aging (as suggested by the importance of TrkB in development)?

- Under disease conditions, is altered NT expression and function secondary to the insult (e.g., inflammation) or are NTs themselves triggers of disease states (as suggested by airway hyper reactivity induced by NTs such as NGF, which could be derived from nerves)? Again, it may be that specific NTs (e.g., NGF or BDNF) targeting specific lung components (e.g., immune cells) are indeed causative of disease, while others are modulated in response to disease. Both themes lend themselves to further exploration into the diagnostic and therapeutic potentials of NTs.

With the use of biochemical, molecular, cellular and animal-based technologies, further advances in understanding and integrating NT function in the lung can be expected. This will require integration of information derived from in vitro cellular work and animal experiments, with corroborations to human samples, potentially derived from normal versus diseased lungs. This is facilitated by the high level of homology of NTs and their receptors across species. However, one issue is the concordance of NT signaling versus physiological regulation in animal models versus humans, especially in the lung (e.g., species heterogeneity in neural control of airways and pulmonary vasculature; differences in immune profiles and responses to the same stimulus), which may mean different profiles of NT/receptor expression and function.

\section{Five-year view}

Neurotrophins appear to be key players in the lung. Studies in the near future should focus on better identifying and delineating the specific mechanisms by which particular NTs work at different levels in the lung, taking advantage of the tremendous amount of data available from other cell systems. These studies are possible using current technologies and our improved understanding of lung biology. As these studies progress, the use of NTs (or their signaling mechanisms) as diagnostic markers for lung health and disease are a distinct possibility. In the near future, it is likely that small-molecule antagonists targeting NTs or their receptors will be explored as therapeutic options. Here, techniques for delivery and specific targeting will need to be developed. Small molecule inhibitors, nanoparticle technology, viral vectors, tissue scaffolds and other emerging approaches may be useful.

\section{Key issues}

- Neurotrophins (NTs) are a family of growth factors long recognized to regulate neuronal growth, differentiation and survival. NTs and their high-affinity receptors (Trks) and low-affinity receptor (p75NTR) have now been found in the lung. Exploration of their role in lung health and disease is ongoing.

- Different cellular components of the lung such as the epithelium, innervation, smooth muscle and immune cells show a heterogeneous pattern of NT and receptor expression. Thus, in the lung, multiple sources of, and targets for, NTs exist.

- Neurotrophins may influence neural control of the airway, alter the balance between bronchoconstriction and bronchodilation, modulate cell proliferation versus apoptosis, and affect the pattern of immunity within the lung. 
- Recent and ongoing studies suggest that NT signaling may be important in a number of lung diseases, such as rhinitis, asthma, bronchitis and even lung cancer.

- As our understanding of NT signaling in the lung advances, we may be able to use this family of growth factors in diagnosis and even therapy for different lung diseases.

\section{References}

Papers of special note have been highlighted as:

- of interest

•• of considerable interest

1. Levi-Montalcini R. The saga of the nerve growth factor. Neuroreport 1998;9:R71-R83. [PubMed: 9858356]. $•$ Nerve growth factor was discovered more than 50 years ago, with Levi-Montalcini sharing the Nobel prize for this work. This conversation with Levi-Montalcini provides a list of the original articles about nerve growth factor.

2. Hennigan A, O'Callaghan RM, Kelly AM. Neurotrophins and their receptors: roles in plasticity, neurodegeneration and neuroprotection. Biochem. Soc. Trans 2007;35(Pt 2):424-427. [PubMed: 17371291]

3. Reichardt LF. Neurotrophin-regulated signalling pathways. Philos. Trans. R. Soc. Lond. B Biol. Sci 2006;361:1545-1564. [PubMed: 16939974] . Description of the signaling mechanisms of neurotrophins (NTs).

4. Lu B, Pang PT, Woo NH. The yin and yang of neurotrophin action. Nat. Rev. Neurosci 2005;6:603614. [PubMed: 16062169]

5. Blum R, Konnerth A. Neurotrophin-mediated rapid signaling in the central nervous system: mechanisms and functions. Physiology 2005;20:70-78. [PubMed: 15653842]

6. Teng KK, Hempstead BL. Neurotrophins and their receptors: signaling trios in complex biological systems. Cell. Mol. Life Sci 2004;61:35-48. [PubMed: 14704852]

7. Chao MV, Rajagopal R, Lee FS. Neurotrophin signalling in health and disease. Clin. Sci. (Lond.) 2006;110:167-173. [PubMed: 16411893]

8. Lykissas MG, Batistatou AK, Charalabopoulos KA, Beris AE. The role of neurotrophins in axonal growth, guidance, and regeneration. Curr. Neurovasc. Res 2007;4:143-151. [PubMed: 17504212]

9. Kalb R. The protean actions of neurotrophins and their receptors on the life and death of neurons. Trends Neurosci 2005;28:5-11. [PubMed: 15626491]

10. Saragovi HU, Hamel E, Di Polo A. A neurotrophic rationale for the therapy of neurodegenerative disorders. Curr. Alzheimer Res 2009;6:419-423. [PubMed: 19874265]

11. Schulte-Herbruggen O, Jockers-Scherubl MC, Hellweg R. Neurotrophins: from pathophysiology to treatment in Alzheimer's disease. Curr. Alzheimer Res 2008;5:38-44. [PubMed: 18288930]

12. Thiele CJ, Li Z, McKee AE. On Trk - the TrkB signal transduction pathway is an increasingly important target in cancer biology. Clin. Cancer Res 2009;15:5962-5967. [PubMed: 19755385]

13. Blesch A, Tuszynski MH. Spontaneous and neurotrophin-induced axonal plasticity after spinal cord injury. Prog. Brain Res 2002;137:415-423. [PubMed: 12440384]

14. Dwivedi Y. Brain-derived neurotrophic factor: role in depression and suicide. Neuropsychiatr. Dis. Treat 2009;5:433-449. [PubMed: 19721723]

15. Skaper SD. The biology of neurotrophins, signalling pathways, and functional peptide mimetics of neurotrophins and their receptors. CNS Neurol. Disord. Drug Targets 2008;7:46-62. [PubMed: 18289031]

16. Lessmann V, Brigadski T. Mechanisms, locations, and kinetics of synaptic BDNF secretion: an update. Neurosci. Res 2009;65:11-22. [PubMed: 19523993] 
17. Lessmann V, Gottmann K, Malcangio M. Neurotrophin secretion: current facts and future prospects. Prog. Neurobiol 2003;69:341-374. [PubMed: 12787574]

18. McDonald NQ, Chao MV. Structural determinants of neurotrophin action. J. Biol. Chem 1995;270:19669-19672. [PubMed: 7649974]

19. Robinson RC, Radziejewski C, Stuart DI, Jones EY. Structure of the brain-derived neurotrophic factor/neurotrophin 3 heterodimer. Biochemistry 1995;34:4139-4146. [PubMed: 7703225]

20. Butte MJ, Hwang PK, Mobley WC, Fletterick RJ. Crystal structure of neurotrophin-3 homodimer shows distinct regions are used to bind its receptors. Biochemistry 1998;37:16846-16852. [PubMed: 9836577]

21. Barker PA. p75NTR is positively promiscuous: novel partners and new insights. Neuron 2004;42:529-533. [PubMed: 15157416]

22. Blochl A, Blochl R. A cell-biological model of p75NTR signaling. J. Neurochem 2007;102:289-305. [PubMed: 17437539]

23. Chen Y, Zeng J, Cen L, et al. Multiple roles of the p75 neurotrophin receptor in the nervous system. J. Int. Med. Res 2009;37:281-288. [PubMed: 19383220]

24. Conover JC, Yancopoulos GD. Neurotrophin regulation of the developing nervous system: analyses of knockout mice. Rev. Neurosci 1997;8:13-27. [PubMed: 9402642]

25. Yamashita T, Fujitani M, Hata K, Mimura F, Yamagishi S. Diverse functions of the p 75 neurotrophin receptor. Anat. Sci. Int 2005;80:37-41. [PubMed: 15794129]

26. Underwood CK, Coulson EJ. The p75 neurotrophin receptor. Int. J. Biochem. Cell Biol 2008;40:1664-1668. [PubMed: 17681869]

27. Kovalchuk Y, Holthoff K, Konnerth A. Neurotrophin action on a rapid timescale. Curr. Opin. Neurobiol 2004;14:558-563. [PubMed: 15464888]

28. Carvalho AL, Caldeira MV, Santos SD, Duarte CB. Role of the brain-derived neurotrophic factor at glutamatergic synapses. Br. J. Pharmacol 2008;153 Suppl. 1:S310-S324. [PubMed: 18059328]

29. Rose CR, Blum R, Kafitz KW, Kovalchuk Y, Konnerth A. From modulator to mediator: rapid effects of BDNF on ion channels. Bioessays 2004;26:1185-1194. [PubMed: 15499580]

30. Nockher WA, Renz H. Neurotrophins in clinical diagnostics: pathophysiology and laboratory investigation. Clin. Chim. Acta 2005;352:49-74. [PubMed: 15653100]

31. Sariola H. The neurotrophic factors in non-neuronal tissues. Cell. Mol. Life Sci 2001;58:1061-1066. [PubMed: 11529499]

32. Luther JA, Birren SJ. Neurotrophins and target interactions in the development and regulation of sympathetic neuron electrical and synaptic properties. Auton. Neurosci 2009;151:46-60. [PubMed: 19748836]

33. Ernsberger U. Role of neurotrophin signalling in the differentiation of neurons from dorsal root ganglia and sympathetic ganglia. Cell Tissue Res 2009;336:349-384. [PubMed: 19387688]

34. Mantilla CB, Zhan WZ, Sieck GC. Neurotrophins improve neuromuscular transmission in the adult rat diaphragm. Muscle Nerve 2004;29:381-386. [PubMed: 14981737]

35. Raap U, Kapp A. Neuroimmunological findings in allergic skin diseases. Curr. Opin. Allergy Clin. Immunol 2005;5:419-424. [PubMed: 16131917]

36. Schiller LR. New and emerging treatment options for chronic constipation. Rev. Gastroenterol. Disord 2004;4 Suppl. 2:S43-S51. [PubMed: 15184816]

37. Caporali A, Emanueli C. Cardiovascular actions of neurotrophins. Physiol. Rev 2009;89:279-308. [PubMed: 19126759]

38. Ricci A, Graziano P, Bronzetti E, et al. Increased pulmonary neurotrophin protein expression in idiopathic interstitial pneumonias. Sarcoidosis Vasc. Diffuse Lung Dis 2007;24:13-23. [PubMed: 18069415]

39. Ricci A, Felici L, Mariotta S, et al. Neurotrophin and neurotrophin receptor protein expression in the human lung. Am. J. Respir. Cell Mol. Biol 2004;30:12-19. [PubMed: 12791675] . • One of the earliest papers to describe the localization of neutrophins and their receptors in the human lung.

40. Virchow JC, Julius P, Lommatzsch M, et al. Neurotrophins are increased in bronchoalveolar lavage fluid after segmental allergen provocation. Am. J. Respir. Crit. Care Med 1998;158:2002-2005. [PubMed: 9847299] 
41. Rochlitzer S, Nassenstein C, Braun A. The contribution of neurotrophins to the pathogenesis of allergic asthma. Biochem. Soc. Trans 2006;34(Pt 4):594-599. [PubMed: 16856870] • A recent review of the role of NTs in asthma, summarizing work by several European groups that have examined this issue using mouse and in vitro models.

42. Raap U, Braunstahl GJ. The role of neurotrophins in the pathophysiology of allergic rhinitis. Curr. Opin. Allergy Clin. Immunol 2010;10:8-13. [PubMed: 19935061] . • A very recent review that highlights the increasing interest in NTs in the upper airway.

43. Nockher WA, Renz H. Neurotrophins and asthma: novel insight into neuroimmune interaction. J. Allergy Clin. Immunol 2006;117:67-71. [PubMed: 16387586]

44. Nockher WA, Renz H. Neurotrophins in allergic diseases: from neuronal growth factors to intercellular signaling molecules. J. Allergy Clin. Immunol 2006;117:583-589. [PubMed: 16522457]

45. Kobayashi H, Gleich GJ, Butterfield JH, Kita H. Human eosinophils produce neurotrophins and secrete nerve growth factor on immunologic stimuli. Blood 2002;99:2214-2220. [PubMed: 11877300]

46. Noga O, Englmann C, Hanf G, et al. The production, storage and release of the neurotrophins nerve growth factor, brain-derived neurotrophic factor and neurotrophin- 3 by human peripheral eosinophils in allergics and non-allergics. Clin. Exp. Allergy 2003;33:649-654. [PubMed: 12752594]

47. Toyoda M, Nakamura M, Makino T, Morohashi M. Localization and content of nerve growth factor in peripheral blood eosinophils of atopic dermatitis patients. Clin. Exp. Allergy 2003;33:950-955. [PubMed: 12859452]

48. Noga O, Englmann C, Hanf G, et al. Activation of the specific neurotrophin receptors TrkA, TrkB and TrkC influences the function of eosinophils. Clin. Exp. Allergy 2002;32:1348-1354. [PubMed: 12220474]

49. Hamada A, Watanabe N, Ohtomo H, Matsuda H. Nerve growth factor enhances survival and cytotoxic activity of human eosinophils. Br. J. Haematol 1996;93:299-302. [PubMed: 8639420]

50. Raap U, Fokkens W, Bruder M, et al. Modulation of neurotrophin and neurotrophin receptor expression in nasal mucosa after nasal allergen provocation in allergic rhinitis. Allergy 2008;63:468475. [PubMed: 18266897]

51. Piedimonte G. Contribution of neuroimmune mechanisms to airway inflammation and remodeling during and after respiratory syncytial virus infection. Pediatr. Infect. Dis. J 2003;22(2 Suppl.):S66S74. [PubMed: 12671455] . Focuses on the role of NTs in viral infections, especially in the pediatric airway. Reviews the role of tachykinins in airway innervation.

52. Noga O, Peiser M, Altenahr M, et al. Differential activation of dendritic cells by nerve growth factor and brain-derived neurotrophic factor. Clin. Exp. Allergy 2007;37:1701-1708. [PubMed: 17892512]

53. Noga O, Peiser M, Altenahr M, et al. Selective induction of nerve growth factor and brain-derived neurotrophic factor by LPS and allergen in dendritic cells. Clin. Exp. Allergy 2008;38:473-479. [PubMed: 18167124]

54. Hikawa S, Kobayashi H, Hikawa N, et al. Expression of neurotrophins and their receptors in peripheral lung cells of mice. Histochem. Cell Biol 2002;118:51-58. [PubMed: 12122447]

55. Santambrogio L, Benedetti M, Chao MV, et al. Nerve growth factor production by lymphocytes. J. Immunol 1994;153:4488-4495. [PubMed: 7963523]

56. Lambiase A, Bracci-Laudiero L, Bonini S, et al. Human CD4 ${ }^{+} \mathrm{T}$ cell clones produce and release nerve growth factor and express high-affinity nerve growth factor receptors. J. Allergy Clin. Immunol 1997;100:408-414. [PubMed: 9314355]

57. Kerschensteiner M, Gallmeier E, Behrens L, et al. Activated human T cells, B cells. and monocytes produce brain-derived neurotrophic factor in vitro and in inflammatory brain lesions: a neuroprotective role of inflammation? J. Exp. Med. 1999;189:865-870.

58. Crystal RG, Randell SH, Engelhardt JF, Voynow J, Sunday ME. Airway epithelial cells: current concepts and challenges. Proc. Am. Thorac. Soc 2008;5:772-777. [PubMed: 18757316]

59. Othumpangat S, Gibson LF, Samsell L, Piedimonte G. NGF is an essential survival factor for bronchial epithelial cells during respiratory syncytial virus infection. PLoS One 2009;4:e6444. [PubMed: 19649262] 
60. Hahn C, Islamian AP, Renz H, Nockher WA. Airway epithelial cells produce neurotrophins and promote the survival of eosinophils during allergic airway inflammation. J. Allergy Clin. Immunol 2006;117:787-794. [PubMed: 16630935]

61. Lommatzsch M, Braun A, Renz H. Neurotrophins in allergic airway dysfunction: what the mouse model is teaching us. Ann. NY Acad. Sci 2003;992:241-249. [PubMed: 12794063]

62. Fox AJ, Patel HJ, Barnes PJ, Belvisi MG. Release of nerve growth factor by human pulmonary epithelial cells: role in airway infammatory diseases. Eur. J. Pharmacol 2001;424:159-162. [PubMed: 11476762]

63. Sonar SS, Schwinge D, Kilic A, et al. Nerve growth factor enhances Clara cell proliferation after lung injury. Eur. Respir. J. DOI: 10.1183/09031936.00165508 (2010) (Epub ahead of print).

64. Meuchel, L.; Townsend, E.; Thompson, M.; Pabelick, C.; Prakash, Y. Effect of neurotrophins on NO generation in airway epithelial cells. Presented at: International Conference of the American Thoracic Society; 14-19 May 2010; New Orleans, LA, USA. (Abstract).

65. Prakash YS, Iyanoye A, Ay B, Mantilla CB, Pabelick CM. Neurotrophin effects on intracellular $\mathrm{Ca}^{2+}$ and force in airway smooth muscle. Am. J. Physiol. Lung Cell. Mol. Physiol 2006;291:L447L456. [PubMed: 16648236]

66. Prakash YS, Thompson MA, Pabelick CM. Brain-derived neurotrophic factor in TNF-a modulation of $\mathrm{Ca}^{2+}$ in human airway smooth muscle. Am. J. Respir. Cell Mol. Biol 2009;41:603-611. [PubMed: 19213875]

67. Kraemer R, Nguyen H, March KL, Hempstead B. NGF activates similar intracellular signaling pathways in vascular smooth muscle cells as PDGF-BB but elicits different biological responses. Arterioscler. Thromb. Vasc. Biol 1999;19:1041-1050. [PubMed: 10195934]

68. Wang S, Bray P, McCaffrey T, et al. p75(NTR) mediates neurotrophin-induced apoptosis of vascular smooth muscle cells. Am. J. Pathol 2000;157:1247-1258. [PubMed: 11021829]

69. Kemi C, Grunewald J, Eklund A, Hoglund CO. Differential regulation of neurotrophin expression in human bronchial smooth muscle cells. Respir. Res 2006;7:18. [PubMed: 16441896]

70. Hamid Q, Tulic M. Immunobiology of asthma. Annu. Rev. Physiol 2009;71:489-507. [PubMed: 19575684]

71. Brightling C, Berry M, Amrani Y. Targeting TNF-a: a novel therapeutic approach for asthma. J. Allergy Clin. Immunol 2008;121:5-10. quiz 11-12. [PubMed: 18036647]

72. Racke K, Matthiesen S. The airway cholinergic system: physiology and pharmacology. Pulm. Pharmacol . Ther 2004;17:181-198. [PubMed: 15219263]

73. Canning BJ. Reflex regulation of airway smooth muscle tone. J. Appl. Physiol 2006;101:971-985. [PubMed: 16728519]

74. Verhein KC, Fryer AD, Jacoby DB. Neural control of airway inflammation. Curr. Allergy Asthma Rep 2009;9:484-490. [PubMed: 19814922]

75. Groneberg DA, Harrison S, Dinh QT, Geppetti P, Fischer A. Tachykinins in the respiratory tract. Curr. Drug Targets 2006;7:1005-1010. [PubMed: 16918328]

76. Frossard N, Freund V, Advenier C. Nerve growth factor and its receptors in asthma and inflammation. Eur. J. Pharmacol 2004;500:453-465. [PubMed: 15464052] . A review focusing on potential sources and targets of nerve growth factor in the lung.

77. Freund-Michel V, Frossard N. The nerve growth factor and its receptors in airway inflammatory diseases. Pharmacol. Ther 2008;117:52-76. [PubMed: 17915332]

78. Hoyle GW, Graham RM, Finkelstein JB, et al. Hyperinnervation of the airways in transgenic mice overexpressing nerve growth factor. Am. J. Respir. Cell Mol. Biol 1998;18:149-157. [PubMed: 9476901]

79. Braun A, Lommatzsch M, Neuhaus-Steinmetz U, et al. Brain-derived neurotrophic factor (BDNF) contributes to neuronal dysfunction in a model of allergic airway inflammation. Br. J. Pharmacol 2004;141:431-440. [PubMed: 14718253]

80. Xu M, Remillard CV, Sachs BD, et al. p75 neurotrophin receptor regulates agonist-induced pulmonary vasoconstriction. Am. J. Physiol. Heart Circ. Physiol 2008;295:H1529-H1538. [PubMed: 18689502]

81. Nico B, Mangieri D, Benagiano V, Crivellato E, Ribatti D. Nerve growth factor as an angiogenic factor. Microvasc. Res 2008;75:135-141. [PubMed: 17764704] 
82. Campos X, Munoz Y, Selman A, et al. Nerve growth factor and its high-affinity receptor TrkA participate in the control of vascular endothelial growth factor expression in epithelial ovarian cancer. Gynecol. Oncol 2007;104:168-175. [PubMed: 16935322]

83. Ejiri J, Inoue N, Kobayashi S, et al. Possible role of brain-derived neurotrophic factor in the pathogenesis of coronary artery disease. Circulation 2005;112:2114-2120. [PubMed: 16186425]

84. Ricci A, Greco S, Amenta F, et al. Neurotrophins and neurotrophin receptors in human pulmonary arteries. J. Vasc. Res 2000;37:355-363. [PubMed: 11025398]

85. Meuchel, L.; Thompson, M.; Pabelick, C.; Prakash, Y. Neurotrophins induce NO generation in pulmonary artery endothelial cells. Presented at: Experimental Biology; 24-28 April 2010; Anaheim, CA, USA. 2010. (Abstract).

86. Ricci A, Bronzetti E, Mannino F, et al. Elevated neurotrophin and neurotrophin receptor expression in spontaneously hypertensive rat lungs. Growth Factors 2004;22:195-205. [PubMed: 15518243]

87. Lommatzsch M, Quarcoo D, Schulte-Herbruggen O, et al. Neurotrophins in murine viscera: a dynamic pattern from birth to adulthood. Int. J. Dev. Neurosci 2005;23:495-500. [PubMed: 15978771]

88. Garcia-Suarez O, Perez-Pinera P, Laura R, et al. TrkB is necessary for the normal development of the lung. Respir. Physiol. Neurobiol 2009;167:281-291. [PubMed: 19523540]

89. Lommatzsch M, Braun A, Mannsfeldt A, et al. Abundant production of brain-derived neurotrophic factor by adult visceral epithelia. Implications for paracrine and target-derived neurotrophic functions. Am. J. Pathol 1999;155:1183-1193. [PubMed: 10514401]

90. Chen X, Ye H, Kuruvilla R, et al. A chemical-genetic approach to studying neurotrophin signaling. Neuron 2005;46:13-21. [PubMed: 15820690]

91. Hack M, Taylor HG, Drotar D, et al. Chronic conditions, functional limitations, and special health care needs of school-aged children born with extremely low-birth-weight in the 1990s. JAMA 2005;294:318-325. [PubMed: 16030276]

92. Yao Q, Zaidi SI, Haxhiu MA, Martin RJ. Neonatal lung and airway injury: a role for neurotrophins. Semin. Perinatol 2006;30:156-162. [PubMed: 16813975] • A review of the potential role of NTs in bronchopulmonary dysplasia.

93. Yao Q, Haxhiu MA, Zaidi SI, et al. Hyperoxia enhances brain-derived neurotrophic factor and tyrosine kinase B receptor expression in peribronchial smooth muscle of neonatal rats. Am. J. Physiol. Lung Cell Mol. Physiol 2005;289:L307-L314. [PubMed: 15821016]

94. Tortorolo L, Langer A, Polidori G, et al. Neurotrophin overexpression in lower airways of infants with respiratory syncytial virus infection. Am. J. Respir. Crit. Care Med 2005;172:233-237. [PubMed: 15879412]

95. Zaidi SI, Jafri A, Doggett T, Haxhiu MA. Airway-related vagal preganglionic neurons express brainderived neurotrophic factor and TrkB receptors: implications for neuronal plasticity. Brain Res 2005;1044:133-143. [PubMed: 15885212]

96. Sopi RB, Martin RJ, Haxhiu MA, et al. Role of brain-derived neurotrophic factor in hyperoxia-induced enhancement of contractility and impairment of relaxation in lung parenchyma. Am. J. Physiol. Lung Cell Mol. Physiol 2008;295:L348-L355. [PubMed: 18515408]

97. Nassenstein C, Braun A, Nockher WA, Renz H. Neurotrophin effects on eosinophils in allergic infammation. Curr. Allergy Asthma Rep 2005;5:204-211. [PubMed: 15842958]

98. Nassenstein C, Mohring UH, Luttmann W, Virchow JC Jr, Braun A. Differential expression of the neurotrophin receptors p75NTR, TrkA, TrkB and TrkC in human peripheral blood mononuclear cells. Exp. Toxicol. Pathol 2006;57 Suppl. 2:55-63. [PubMed: 16584874]

99. Abram M, Wegmann M, Fokuhl V, et al. Nerve growth factor and neurotrophin-3 mediate survival of pulmonary plasma cells during the allergic airway inflammation. J. Immunol 2009;182:47054712. [PubMed: 19342646]

100. Bennedich, Kahn L.; Gustafsson, LE.; Olgart Hoglund, C. Brain-derived neurotrophic factor enhances histamine-induced airway responses and changes levels of exhaled nitric oxide in guinea pigs in vivo. Eur. J. Pharmacol 2008;595:78-83. [PubMed: 18700138]

101. Dagnell C, Kemi C, Klominek J, et al. Effects of neurotrophins on human bronchial smooth muscle cell migration and matrix metalloproteinase-9 secretion. Transl. Res 2007;150:303-310. [PubMed: 17964519] 
102. Nassenstein C, Dawbarn D, Pollock K, et al. Pulmonary distribution, regulation, and functional role of Trk receptors in a murine model of asthma. J. Allergy Clin. Immunol 2006;118:597-605. [PubMed: 16950277]

103. Renz H, Kerzel S, Nockher WA. The role of neurotrophins in bronchial asthma: contribution of the pan-neurotrophin receptor p75. Prog. Brain Res 2004;146:325-333. [PubMed: 14699972]

104. Braun A, Lommatzsch M, Lewin GR, Virchow JC, Renz H. Neurotrophins: a link between airway inflammation and airway smooth muscle contractility in asthma? Int. Arch. Allergy Immunol 1999;118:163-165. [PubMed: 10224367]

105. Micera A, Vigneti E, Pickholtz D, et al. Nerve growth factor displays stimulatory effects on human skin and lung fibroblasts, demonstrating a direct role for this factor in tissue repair. Proc. Natl Acad. Sci. USA 2001;98:6162-6167. [PubMed: 11344264]

106. Bahat-Stroomza M, Barhum Y, Levy YS, et al. Induction of adult human bone marrow mesenchymal stromal cells into functional astrocyte-like cells: potential for restorative treatment in Parkinson's disease. J. Mol. Neurosci 2009;39:199-210. [PubMed: 19127447]

107. Dekkers BG, Maarsingh H, Meurs H, Gosens R. Airway structural components drive airway smooth muscle remodeling in asthma. Proc. Am. Thorac. Soc 2009;6:683-692. [PubMed: 20008876]

108. Bai TR. Evidence for airway remodeling in chronic asthma. Curr. Opin. Allergy Clin. Immunol 2010;10:82-86. [PubMed: 19858714]

109. Lagente V, Boichot E. Role of matrix metalloproteinases in the inflammatory process of respiratory diseases. J. Mol. Cell. Cardiol 2009;48(3):440-444. [PubMed: 19818795]

110. Fujimaki H, Win-Shwe TT, Yamamoto S, Nakajima D, Goto S. The expression of nerve growth factor in mice lung following low-level toluene exposure. Toxicol. Lett 2009;191:240-245. [PubMed: 19765639]

111. Win-Shwe TT, Yamamoto S, Nakajima D, et al. Modulation of neurological related allergic reaction in mice exposed to low-level toluene. Toxicol. Appl. Pharmacol 2007;222:17-24. [PubMed: 17481687]

112. Fujimaki H, Yamamoto S, Win-Shwe TT, et al. Effect of long-term exposure to low-level toluene on airway inflammatory response in mice. Toxicol. Lett 2007;168:132-139. [PubMed: 17174043]

113. Kimata H. Passive smoking elevates neurotrophin levels in tears. Hum. Exp. Toxicol 2004;23:215217. [PubMed: 15222398]

114. Urrego F, Scuri M, Auais A, Mohtasham L, Piedimonte G. Combined effects of chronic nicotine and acute virus exposure on neurotrophin expression in rat lung. Pediatr. Pulmonol 2009;44:10751084. [PubMed: 19824047]

115. McSharry CP, Fraser I, Chaudhuri R, et al. Nerve growth factor in serum and lymphocyte culture in pigeon fanciers' acute hypersensitivity pneumonitis. Chest 2006;130:37-42. [PubMed: 16840380]

116. Olgart C, Frossard N. Human lung fibroblasts secrete nerve growth factor: effect of inflammatory cytokines and glucocorticoids. Eur. Respir. J 2001;18:115-121. [PubMed: 11510781]

117. Antonelli A, Lapucci G, Vigneti E, Bonini S, Aloe L. Human lung fibroblast response to NGF, IL-1 $\beta$, and dexamethsone. Lung 2005;183:337-351. [PubMed: 16389726]

118. Kruttgen A, Schneider I, Weis J. The dark side of the NGF family: neurotrophins in neoplasias. Brain Pathol 2006;16:304-310. [PubMed: 17107600]

119. Ricci A, Greco S, Mariotta S, et al. Neurotrophins and neurotrophin receptors in human lung cancer. Am. J. Respir. Cell Mol. Biol 2001;25:439-446. [PubMed: 11694449]

120. Ricci A, Graziano P, Mariotta S, et al. Neurotrophin system expression in human pulmonary carcinoid tumors. Growth Factors 2005;23:303-312. [PubMed: 16338793]

121. Perez-Pinera P, Hernandez T, Garcia-Suarez O, et al. The Trk tyrosine kinase inhibitor K252a regulates growth of lung adenocarcinomas. Mol. Cell Biochem 2007;295:19-26. [PubMed: 16862449]

122. Missale C, Codignola A, Sigala S, et al. Nerve growth factor abrogates the tumorigenicity of human small cell lung cancer cell lines. Proc. Natl Acad. Sci. USA 1998;95:5366-5371. [PubMed: 9560282] 
123. Bandtlow C, Dechant G. From cell death to neuronal regeneration, effects of the 75 neurotrophin receptor depend on interactions with partner subunits. Sci. STKE 2004;(235):pe24. [PubMed: 15173600]

124. Lomen-Hoerth C, Shooter EM. Widespread neurotrophin receptor expression in the immune system and other nonneuronal rat tissues. J. Neurochem 1995;64:1780-1789. [PubMed: 7891106]

125. Goss JR. The therapeutic potential of gene transfer for the treatment of peripheral neuropathies. Expert Rev. Mol. Med 2007;9:1-20. [PubMed: 17367556]

126. Webster NJ, Pirrung MC. Small molecule activators of the Trk receptors for neuroprotection. BMC Neurosci 2008;9 Suppl. 2:S1. [PubMed: 19090982]

127. Longo FM, Massa SM. Small molecule modulation of $\mathrm{p} 75$ neurotrophin receptor functions. CNS Neurol. Disord. Drug Targets 2008;7:63-70. [PubMed: 18289033]

128. Nockher WA, Renz H. Neurotrophins in inflammatory lung diseases: modulators of cell differentiation and neuroimmune interactions. Cytokine Growth Factor Rev 2003;14:559-578. [PubMed: 14563357]

129. Hoyle GW. Neurotrophins and lung disease. Cytokine Growth Factor Rev 2003;14:551-558. [PubMed: 14563356]

130. Nassenstein C, Kerzel S, Braun A. Neurotrophins and neurotrophin receptors in allergic asthma. Prog. Brain Res 2004;146:347-367. [PubMed: 14699973] 


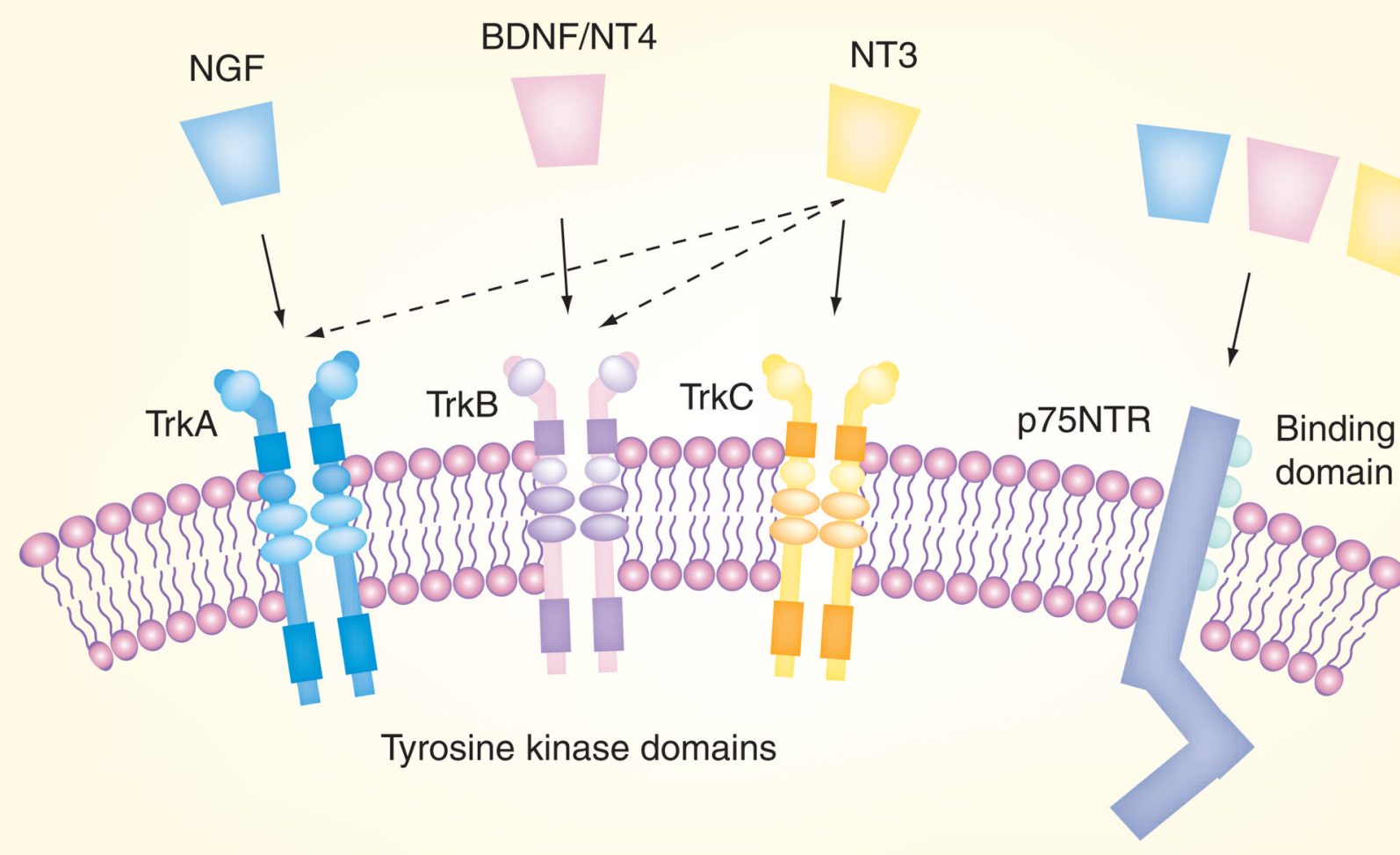

Expert Rev. Resp. Med. @ Future Science Group (2010)

Figure 1. Neurotrophins and their receptors

The family of NTs consists of four polypeptide proteins that bind to two classes of receptor. All NTs bind to the low-affinity p75NTR receptor, a member of the TNF receptor family. The tropomyosin-related kinase (Trk) receptors are a group of high-affinity NT tyrosine kinase receptors and preferentially bind particular NTs. NGF preferentially binds to TrkA (solid arrow). TrkB is the preferred receptor for BDNF and NT4, while TrkC preferentially binds to NT3. NT3 also binds with lesser affinity to TrkA and TrkB (dotted arrows).

BDNF: Brain-derived neurotrophic factor; NGF: Nerve growth factor; NT: Neurotrophin. 


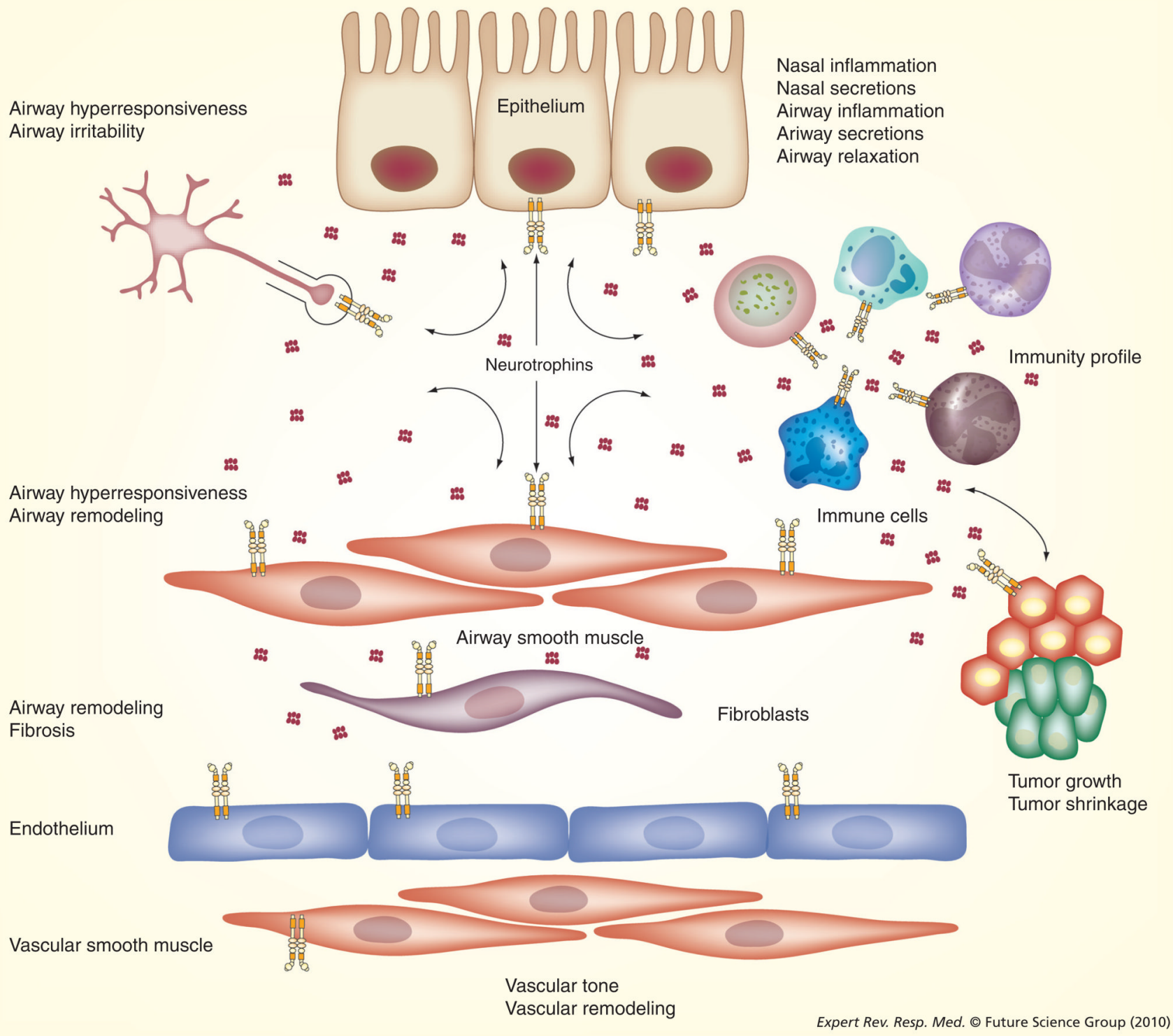

Figure 2. Neurotrophins in the lung

As outlined in the main text, there is increasing evidence that NTs can be produced by, as well as targeted to, a number of lung components. Different NTs are expressed by nasal and airway epithelia, airway and vascular smooth muscle, sensory and other innervation of the lung, different immune cells, other structural cells and even tumors. As described in the article, NTs secreted by a cell type may have autocrine or paracrine effects on adjoining cell types. Thus NT signaling becomes central in the regulation of lung structure and function. In disease states (especially those involving inflammation), increased expression of NTs or their receptors can contribute to structural and functional changes such as enhanced inflammation, increased secretions, airway hyperresponsiveness (but impaired relaxation) and even altered tumor growth. See TABLE 1 for a summary of such effects involving specific NTs and their receptors. NT: Neurotrophin. 


\section{Table 1}

Neurotrophins and their potential functions in the lung.

\begin{tabular}{|c|c|c|c|c|}
\hline Components & $\begin{array}{l}\text { NTs } \\
\text { expressed }\end{array}$ & $\begin{array}{l}\text { Receptors } \\
\text { expressed }\end{array}$ & Effects & NTs in disease \\
\hline \multicolumn{5}{|l|}{ Structural elements } \\
\hline \multirow[t]{3}{*}{ Nasal epithelium } & NGF & TrkA & & $\uparrow N G F$, BDNF, TrkA, p75NTR in rhinitis \\
\hline & BDNF & TrkB & & $\downarrow \mathrm{BDNF}$ and p75NTR, but $\uparrow$ TrkA with infection \\
\hline & & p75NTR & & \\
\hline \multirow[t]{7}{*}{ Bronchial epithelium } & NGF & TrkA & Lung development & $\uparrow B D N F$ in asthma \\
\hline & BDNF & TrkB & $\begin{array}{l}\text { Cell survival (decreased } \\
\text { apoptosis) }\end{array}$ & $\uparrow N G F$, BDNF, TrkA, TrkB, \\
\hline & NT4 & p75NTR & NO release & $\downarrow$ p75NTR with infection \\
\hline & NT3 & & Airway remodeling & $\uparrow N G F$ with inflammation (allergic asthma) \\
\hline & & & & $\uparrow$ TrkB, p75NTR with cigarette smoke \\
\hline & & & & $\begin{array}{l}\uparrow \text { Airway thickening in asthma } \\
\text { or inflammation; } \uparrow \text { cell survival }\end{array}$ \\
\hline & & & & $\uparrow$ Clara cell production (NGF) \\
\hline \multirow[t]{6}{*}{ Airway smooth muscle } & NGF & TrkA & \multirow{3}{*}{$\begin{array}{l}\text { Regulation of airway contractility } \\
\text { ( } \uparrow \text { with NGF, BDNF, NT4 } \\
\downarrow \text { with NT3) }\end{array}$} & $\uparrow N G F$, BDNF, TrkA, TrkB, p75NTR with \\
\hline & BDNF & TrkB & & inflammation (allergic asthma) \\
\hline & NT4 & TrkC & & $\uparrow B D N F$, TrkB with hyperoxia (relevant to BPD) \\
\hline & NT3 & p75NTR & Cell proliferation & $\uparrow$ TrkB, p75NTR with cigarette smoke \\
\hline & & & Airway remodeling & $\uparrow$ Airway hyperresponsiveness (NGF) \\
\hline & & & Lung development (BDNF, TrkB) & $\uparrow$ Cell proliferation (NGF) \\
\hline \multirow[t]{7}{*}{ Nerves } & NGF & TrkA & \multirow{2}{*}{$\begin{array}{l}\uparrow S P \text { content (NGF; sensory } \\
\text { nerves, vagal afferents) }\end{array}$} & $\downarrow \mathrm{p} 75 \mathrm{NTR}$ in rhinitis \\
\hline & BDNF & TrkB & & $\uparrow N G F$ in rhinitis, asthma \\
\hline & NT3 & p75NTR & $\uparrow \mathrm{NK} 1$ receptor expression (NGF) & $\uparrow N G F-i n d u c e d$ TrkA and SP \\
\hline & & & $\uparrow$ Neurotransmitter release (NT3) & $\uparrow$ Neuronal plasticity \\
\hline & & & & $\uparrow$ Cholinergic outflow (BDNF) \\
\hline & & & & Neurally-mediated airway hyperresponsiveness \\
\hline & & & & (NGF, BDNF) \\
\hline \multirow[t]{3}{*}{ Fibroblasts } & NGF & TrkA & Profliferation & $\uparrow N G F$ and BDNF in inflammation \\
\hline & BDNF & TrkB & Migration & $\uparrow$ TrkA and p75NTR with NGF stimulation \\
\hline & & p75NTR & Myofibroblast differentiation & $\uparrow N G F$ and TrkA in idiopathic pulmonary fibrosis \\
\hline \multirow[t]{3}{*}{ Pulmonary endothelium } & NGF & TrkA & NO production & \\
\hline & $\mathrm{BDNF}$ & TrkB & Migration (NGF) & \\
\hline & NT & p75NTR & Proliferation (NGF) & \\
\hline Pulmonary vascular & NGF & TrkB & Proliferation (NGF) & $\uparrow N G F$, BDNF, TrkA, TrkB in pulmonary \\
\hline smooth muscle & & p75NTR & Angiogenesis (NGF) & hypertension \\
\hline Interstitium & & & & $\begin{array}{l}\text { NGF-induced increase in type I collagen and } \\
\text { MMPs }\end{array}$ \\
\hline
\end{tabular}




\begin{tabular}{|c|c|c|c|c|}
\hline Components & $\begin{array}{l}\text { NTs } \\
\text { expressed }\end{array}$ & $\begin{array}{l}\text { Receptors } \\
\text { expressed }\end{array}$ & Effects & NTs in disease \\
\hline Tumors & $\begin{array}{l}\text { NGF (BAC, } \\
\text { SCC, } \\
\text { carcinoid) } \\
\text { BDNF (SCC, } \\
\text { carcinoid) }\end{array}$ & $\begin{array}{l}\text { TrkA } \\
\text { TrkB }\end{array}$ & & $\begin{array}{l}\downarrow \text { Small-cell cancer growth (NGF) } \\
\uparrow \text { Adenocarcinoma (cell line) growth (NGF, } \\
\text { BDNF) }\end{array}$ \\
\hline \multicolumn{5}{|l|}{ Immune cells } \\
\hline \multirow[t]{2}{*}{ Dendritic cells } & NGF & TrkA & IL-10 release & $\uparrow B D N F$ with inflammation \\
\hline & BDNF & TrkB & & $\uparrow \mathrm{IL}-6$ release with inflammation (NGF, BDNF \\
\hline \multirow{3}{*}{$\begin{array}{l}\text { Monocytes/ } \\
\text { macrophages }\end{array}$} & NGF & TrkA & & $\uparrow N G F$ and BDNF with allergen challenge \\
\hline & BDNF & TrkB & & \\
\hline & NT3 & & & \\
\hline \multirow[t]{4}{*}{ T lymphocytes } & NGF & TrkA & & $\uparrow \mathrm{BDNF}$ with allergen challenge \\
\hline & & & & NGF produced by $\mathrm{CD} 4^{+}$and $\mathrm{CD} 8^{+}$ \\
\hline & & & & T lymphocytes \\
\hline & & & & $\uparrow$ NGF by Th2 lymphocytes \\
\hline \multirow[t]{3}{*}{ B lymphocytes } & NGF & TrkA & & $\uparrow N G F$, BDNF, NT3 with allergen challenge \\
\hline & BDNF & p75NTR & & \\
\hline & NT3 & & & \\
\hline \multirow[t]{4}{*}{ Eosinophils } & NGF & TrkA & $\uparrow$ Cell survival & $\uparrow N G F$ with rhinitis, airway inflammation \\
\hline & BDNF & & IL-4 release (NGF) & $\uparrow$ TrkA with infection \\
\hline & NT4 & & & $\uparrow \mathrm{IL}-4$ release in rhinitis (NGF) \\
\hline & NT3 & & & $\uparrow E P X$ in rhinitis (BDNF) \\
\hline Neutrophils & & TrkB & & \\
\hline \multirow[t]{3}{*}{ Mast cells } & NGF & TrkA & & Allergen-induced IgE-mediated NGF release \\
\hline & BDNF & TrkB & & \\
\hline & NT3 & p75NTR & & \\
\hline \multirow[t]{2}{*}{ Basophils } & NGF & TrkA & & \\
\hline & & p75NTR & & \\
\hline \multicolumn{5}{|l|}{ Fluids } \\
\hline \multirow[t]{3}{*}{ Blood } & NGF & & & $\uparrow N G F$, BDNF in rhinitis and asthma \\
\hline & BDNF & & & $\uparrow N G F$ with pollutant exposure \\
\hline & & & & $\uparrow N G F$ and p75NTR with nicotine exposure \\
\hline \multirow[t]{3}{*}{ BAL } & NGF & & & $\uparrow N G F, B D N F$ and NT3 in asthma \\
\hline & BDNF & & & \\
\hline & NT3 & & & \\
\hline Nasal lavage & NGF & & & $\uparrow N G F$ in rhinitis and asthma \\
\hline
\end{tabular}


Information summarized from multiple reports based on (mostly) human and animal work. See $[42,76,77,102,128-130]$ for more detailed reviews on the distribution of NTs and their receptors, as well as their potential functions in the airway and lung.

BAC: Bronchioloalveolar carcinoma; BDNF: Brain-derived neurotrophic factor; BPD: Bronchopulmonary dysplasia; EPX: Eosinophil protein X; MMP: Matrix metalloproteinase; NGF: Nerve growth factor; NK: Neurokinin; NO: Nitric oxide; NT: Neurotrophin; SCC: Squamous cell carcinoma; SP: Substance P; Trk: Tropomyosin-receptor-kinase. 